\title{
Development and functioning of FX markets in Asia and the Pacific ${ }^{1}$
}

\author{
Richard M Levich ${ }^{2}$ and Frank Packer ${ }^{3}$
}

\begin{abstract}
Global foreign exchange (FX) trading volume in traditional FX products and derivatives in Asia and the Pacific has expanded rapidly over the last 15 years, more so than in other regions. Asian currencies also have experienced exceptional growth in offshore turnover, including that of non-deliverable forwards (NDFs). Trading activity on this scale, spread across many countries and currencies, underscores the need for a smoothly functioning infrastructure and exceptional risk management processes. While settlement risks are mitigated for the vast majority of turnover through systems such as CLS Bank, the Asia-Pacific region would benefit by having more countries and currencies become CLS-enabled or tradable under other payment-versus-payment (PVP) systems. Although their volatility was less pronounced than during the global financial crisis, FX markets in the region experienced added turbulence during the "taper tantrum" of 2013. High-turnover currencies tended to depreciate more after the taper announcements, although volatility rose more sharply in currencies with low turnover. The FX market is a prominent venue for carry trades that are subject to crash risk. While there is some evidence of herding behaviour exacerbating this risk over the past decade, the measures calibrated more recently do not suggest exceptional crowding into carry trades ahead of the "taper tantrum" in 2013. At the same time, our measures of crowdedness for the carry trade show considerable variation over time. It might be useful to make crowdedness measures publicly available.
\end{abstract}

1 We thank Jimmy Shek for his research assistance and participants at a BIS workshop in 2013 for helpful comments on an initial outline. We have also benefited from the remarks of participants at the 2014 conference in Wellington, in particular from discussant Takatoshi Ito. We also thank Mychal Campos, Sammie Chan, Juan Gutierrez, Rachel Hoey, Dino Kos and Andreas Schrimpf for comments. The views expressed here are those of the authors and do not necessarily reflect those of the BIS.

2 Professor of Finance and International Business and Deputy Chair of the Department of Finance, Stern School of Business, New York University, New York, New York and NBER.

3 Regional Adviser, Representative Office for Asia and the Pacific, Bank for International Settlements, Hong Kong SAR. Work on the conference and related volume was done while Mr. Packer was Head of Economics and Financial Markets at the Representative Office for Asia and the Pacific. 


\section{Introduction}

Global foreign exchange (FX) trading volume has expanded rapidly in recent years. According to BIS data, daily turnover in traditional FX products and derivatives grew from an estimated $\$ 590$ billion in 1989 to $\$ 5.3$ trillion in 2013. Between 2010 and 2013 alone, turnover increased by $35 \%$. The trading volume in the currencies of the 12 Asia-Pacific jurisdictions that are the focus of this paper - Australia, China, Hong Kong SAR, India, Indonesia, Japan, Korea, Malaysia, the Philippines, Singapore, Thailand and New Zealand - have increased even more quickly over the past three years, at $56 \%$. Trading activity on this scale, spread across this many countries and currencies, underscores the need for a smoothly functioning infrastructure and exceptional risk management processes.

Our paper is organised as follows. Part 2 will cover recent trends in FX markets in Asia and the Pacific, presenting salient facts from the BIS Triennial Central Bank Survey of foreign exchange and derivatives market activity, including growth, location of turnover for the major Asia-Pacific currencies as well as turnover by counterparty. Part 3 will shift attention to the evolution of institutional safeguards in FX trading, notably CLS Bank and its role in enhancing FX market resilience during the global financial crisis (GFC) in 2008-09, as well as the current situation and outlook for the evolution of institutional safeguards in Asia-Pacific. Part 4 will present a brief conjunctural analysis of the resilience of market functioning in Asian currencies over the past decade and a half, while Part 5 will then focus on a particular type of trade - the carry trade - which has at times accounted for a sizeable proportion of FX transactions in the Asia-Pacific currencies. Using newly developed measures of crowdedness and liquidity, we ask how prevalent the carry trade has been and what is the evidence concerning its contribution to instability in FX markets in the region, most notably during the global financial crisis and the more recent "taper tantrum" episodes in 2013.

\section{Trends and patterns in FX trading in Asia-Pacific: Evidence from the Triennial Survey}

The 2013 BIS Triennial Survey gives a snapshot of evolving trends in the FX markets, and allows us to gauge how future economic expansion and possible institutional changes in the region might impact FX trading activity and risk exposures. Conducted every three years since 1989, the latest survey was completed in 2013. Some 53 central banks participated and collected data from about 1,300 banks and dealers about their FX trading activity during April. Turnover in more than 40 currencies was reported for spot, outright forwards, FX swaps, currency swaps and FX options transactions.

\section{2.a Trading in Asia-Pacific currencies vs others}

While the latest triennial survey documented robust global growth in FX turnover, the Asia-Pacific currencies showed stronger growth on the whole than other major currencies. Table 2.1 documents the evolving share of foreign exchange market turnover for the six most actively traded currencies of advanced economies, as well 
as for the New Zealand dollar. The three currencies of the Asia-Pacific economies (JPY/AUD/NZD) have gained share since 2010 relative to other advanced economy currencies, rising to $23 \%,{ }^{4} 9 \%$ and $2 \%$ of overall turnover, respectively, well above the shares of the 2010 survey, as well as those of the survey of nine years earlier (2004). The 2010-13 growth rates of the yen, Australian and New Zealand dollars of $63 \%, 53 \%$ and $66 \%$ were well above overall growth rates of turnover, both for advanced economy currencies (34\%) and for the global sample of currencies (35\%).

Similarly, turnover in many of the currencies of emerging market economies in Asia-Pacific have grown relatively rapidly (Table 2.2). The fastest growing currency is the Chinese renminbi: its turnover grew by 249\% between 2010 and 2013, and it now comprises the second largest share of trading among emerging market currencies (after the Mexican peso). The Thai baht, Malaysian ringgit, Indonesian rupiah and Indian rupee all show very robust growth well above global averages at $123 \%, 95 \%, 50 \%$ and $40 \%$, respectively. Similar to other emerging market economy (EME) currencies, growth in turnover has been far in excess of related country trade growth, consistent with the ongoing "financialisation" of currencies (McCauley and Scatigna (2011)). The one biggest single exception to robust growth has been the Hong Kong dollar, where a decline of $17.6 \%$ since 2010 likely reflects its displacement by the renminbi in a significant number of transactions in Hong Kong SAR.

The triennial survey also shows that the US dollar (USD) remains the dominant global currency, as one of the currencies in more than $87 \%$ of transactions globally (Table 2.1). Asian currencies also overwhelmingly trade against the USD, though at proportions somewhat lower than the global average. For the bulk of this paper, when we focus on issues of liquidity and performance of FX trades in Asia, we will focus on the USD pairs of Asia-Pacific currencies. The potential for other currencies to rise as significant alternatives to the US dollar - a phenomenon which has not yet been observed in the BIS Triennial Survey - we leave for other research.

\section{2.b Offshore trading}

FX trading is increasingly taking place offshore, or outside the jurisdiction where a currency is issued. Indeed, the past few triennial surveys have shown that the offshore share of total FX transactions to be steadily rising across a broad spectrum of currencies. As a result, growth in EME currencies has been much more buoyant than the growth of FX transactions taking place in EME jurisdictions (71\% vs $32 \%$, from 2010 to 2013).

Table 2.3 lists the offshore trading of currencies in the Asia-Pacific alongside some comparable currencies. Among advanced economies, the Japanese yen, and Australian and New Zealand dollar have significantly higher offshore shares in global turnover than other advanced economy currencies on average, ranging between $83 \%$ and $93 \%$. The growth in offshore trading since 2007 also outpaces advanced country currency averages as well.

4 Increases in Japanese yen trading relative to the 2010 survey were in part due to a surge in late 2012 and early 2013 due to expectations and implementation of a change in economic and monetary policy in Japan. Data from other FX surveys show signs of a subsequent decline from the peak (Bech and Sobrun (2013)). 
Among emerging market currencies, once again the renminbi stands out, with by far the largest share of offshore trading at $72 \%$, or $\$ 86.1$ billion per day. Growth in renminbi offshore trading since 2007 has been $56 \%$, on an annualised basis. At the same time, the offshore trading of most other Asia currencies also grew significantly more rapidly than the average for emerging market currencies, at annual rates of $40 \%, 30 \%, 26 \%, 24 \%$, and $23 \%$ for the Malaysian ringgit, Indian rupee, Thai baht, the Philippine peso, and Indonesia rupiah, respectively (Table 2.3). Overall, growth in the daily offshore turnover of Asian EME currencies contributed 35 percentage points to their total growth of $41 \%$ in the $2010-13$ period (Ehlers and Packer (2013)).

Compared with other emerging market currencies, emerging Asian currencies are by far the most traded within their geographical region. More than a quarter of trading takes place both offshore and within emerging Asia. The renminbi is increasingly prominent in this respect: nearly two thirds of its offshore volume is in Asia.

But it is not just the renminbi that attests to a strong regional influence of trading in Asian currencies. Some $20-40 \%$ of turnover in the Korean won, Indian rupee, Indonesian rupiah, Malaysian ringgit and the Philippine peso takes place offshore and in Asia, well above the EM average for offshore, intra-regional turnover of $12.6 \%$. The only exceptions here are the Hong Kong and Singapore dollars which tend to trade outside Asia when they trade offshore - possibly because the associated jurisdictions are large offshore trading hubs, themselves with abundant turnover and liquidity across a range of currencies.

That said, the United Kingdom continues to serve as a major offshore trading hub for Asian currencies. Despite the presence of Hong Kong and Singapore, nearly one fifth of trading in emerging Asian currencies trading takes place in the United Kingdom, while the United States lags considerably at 8\%. Hong Kong SAR and Singapore together account for $25.3 \%$ of offshore trading in emerging Asian currencies.

Non-deliverable forwards. London is noted in particular as a hub for trades in non-deliverable forwards (NDFs), ie forward contracts which are valued based on movements in a currency's exchange rate, but settled in US dollars. More than one third of $\$ 127$ billion in daily NDF trading reported by the 2013 Triennial Survey took place in London. (Asian financial centres remain quite important for trading in NDFs in some currencies such as the Chinese renminbi and Korean won.) Not requiring transactions in a currency, NDFs allow investors to speculate in a currency even in the presence of capital flows and trading restrictions, and thus tend to take place offshore (McCauley et al (2014)). They account for one fifth of all forward trading, and have grown rapidly.

There is evidence that, for many currencies including those in Asia, the NDF market has dominated the deliverable venue for price discovery during periods of volatility, perhaps reflecting a tendency for global factors such as VIX to be incorporated more into the pricing of NDFs than that of deliverable forwards. ${ }^{5}$ Below, we will examine the time series of relative pricing in NDF vs deliverable

5 See Goyal et al (2013), Cadarajat and Lubis (2012) and Kim and Song (2010) for evidence in the case of India, Indonesia and Korea. 
forward markets as one of the indicators of liquidity in the currency during periods of turbulence in financial markets.

\section{2.c Turnover by counterparty}

Given its rapid growth, the FX market clearly serves other functions than simply supporting international trade in goods and services, and cross-border international financial transactions in equities, bonds, and other instruments. A large share of trading is the result of dealers trading with one another during the day in an effort to control risk as they respond to order flow from incoming trades and provide liquidity for buys and sells. However, non-dealer financial institutions in Asia-Pacific jurisdictions account for more than one quarter of daily FX trading volume, both in advanced and emerging economies (Table 2.4). The implication is that many nonreporting banks, institutional investors and hedge funds use the FX market to either (a) hedge their outstanding exposure to foreign currency assets and liabilities and the expected cash flows generated by these positions, or (b) take on new risky foreign exchange exposures. In addition, a substantial share of non-dealer bank volume fulfils so-called "prime-brokered" activity whereby third-party financial institutions trade under the name and credit standing of their bank. Given the scale of the FX market and its reach across all countries with distinct regulations, it is essential that the market is not exposed to risks that could jeopardise its operations or the larger financial system. We turn to this issue in the next section.

\section{Institutional safeguards in FX trading}

\section{3.a Risk and regulation in the FX market}

At more than $\$ 5$ trillion per day the global FX market has the largest volume of daily turnover of any financial market. It may be surprising that a market so large and so critical to the global economy is not subject to significant regulatory oversight and does not meet the reporting and transparency standards that are commonly found in organised markets for equities, futures, and even more recent financial innovations such as swaps and other derivative instruments. The explanation for this outcome is partly historical and a function of the market itself, and partly the result of recent innovations intended to mitigate and largely eliminate the major sources of systemic risk in FX trading.

The FX market can be characterised as a globally dispersed, broker-dealer market. The foreign exchange market is not a place one can visit like the New York Stock Exchange or the Chicago Mercantile Exchange. Currency trades in an interbank market through many banks and trading rooms around the world. Trading is facilitated by various electronic trading platforms (some operated by single banks as well as systems developed by Reuters and Electronic Broking Systems [EBS]) but trades facilitated via voice-brokers or simply direct calls between 
dealers remain a significant part of the market. ${ }^{6}$ There are no set standard trading hours, no centralised record of transactions, and no unique closing price as there is for a listed stock or futures contracts.

In their discussion of FX market structure and its evolution, King, Osler and Rime (2011) observe that "The vast majority of FX trading is essentially unregulated, in striking contrast to the extensive regulations in most equity and bond markets." The authors point out that FX dealers could move elsewhere if threatened by regulation. But surely the design of regulations would be daunting, with every currency pair involving two countries and dealers from third countries representing banks headquartered in still other countries. As a result, regulations that are familiar in some markets are absent in the FX market. Short-sale restrictions, for example, would have no meaning in FX as the purchase of one currency is simply the sale of another. Front-running of customer orders is not illegal, but it is heavily discouraged by market convention and best practices. So-called FX Committees in six cities act as self-regulatory organisations to establish standards for traders, relationships with customers, and so on. ${ }^{8}$

That there is minimal regulation implies that there is minimal reporting by banks to regulatory agencies. Data pertaining to specific trades between Bank $A$ and Financial Institution $B$ or Customer $C$ are private information and are therefore not reported to an exchange or central bank. As a result, most research on currency trading relies on proprietary data sets and sometimes reflects data on indicative quotes rather than actual transaction prices, and may reflect only a narrow segment of the market.

The GFC in 2008-09 provided the impetus for policymakers in all countries to reassess their oversight of all financial institutions and marketplaces. In general, the new regulations call for higher capital requirements at banks and greater reliance on the use of central counterparties (CCP) to make trading in certain derivatives more transparent and they also rely on CCP margin requirements and marking to market to lessen the ongoing risks in derivative positions.

Importantly, outright forward and swap transactions (which together accounted for $55 \%$ of global FX trading in 2013) are exempt from the CCP mandate which the Dodd-Frank Act imposes on most derivative transactions. The US Treasury Department, in coordination with other US regulators and other countries, approved the exemption in November 2012. In their proposal brief, the Treasury referred to a number of unique factors that limit the risk in FX swaps and forward markets compared with other derivative markets. ${ }^{9}$ Among these factors, the Treasury cited the shorter duration of FX swaps and forwards (noting that roughly $68 \%$ of the market matures in one week or less, and $98 \%$ matures in one year or less). And, in contrast to other derivatives, FX swaps always require both parties to physically exchange the full amount of currency on fixed terms that are set at the outset of the

6 See 2013 BIS Triennial Survey, Table 26. The data show that voice execution accounts for $34.5 \%$ of spot turnover while electronic execution accounts for $63.8 \%$. Voice accounts for a higher percentage in outright forwards, FX swaps, currency swaps, and $62.0 \%$ for FX options.

7 Exchange-traded FX futures and options are an exception to this general observation.

8 The six cities are London, New York, Tokyo, Toronto, Sydney and Singapore.

9 See US Treasury Department (2011). 
contract. Market participants know the full extent of their own payment obligations and their exposure to their counterparty throughout the life of the contract.

These features could be moot were it not for one last feature of the foreign exchange market which the Treasury described as a "well-functioning settlement process", in reference to CLS Bank. The CLS Bank is undoubtedly the most critical innovation in the last 20 years to touch the infrastructure of the foreign exchange market, especially with respect to safeguarding the market and mitigating the risks of trade settlement. In the remainder of this section we review the historical events leading up to the founding of CLS Bank, together with its structure and activities. Then we gauge its presence in different products, countries and currencies, and discuss what risks remain with special reference to the Asia-Pacific region.

\section{3.b Historical background to the founding of the CLS Bank}

For most of its history, the nature of the foreign exchange market dictated that FX transactions were to be settled on a bilateral basis. Netting systems reduced the gross amount of funds necessary to flow between counterparties, but settling a transaction still required counterparty $A$ to pay away funds in one currency to counterparty B without complete assurance that counterparty B would deliver its leg of the transaction. This possibility became a reality one day in 1974 when Herstatt Bank received Deutsche marks at its offices in Cologne, Germany, but was subsequently closed down and forced to cease operations by German banking regulators, and was thus unable to deliver US dollars to its counterparties once US banks opened for business. This form of credit risk, known as delivery risk (but naturally enough quickly enshrined as "Herstatt risk") resulted in a total loss of principal for Herstatt's counterparties.

Soon afterwards, market participants and regulators began searching for a solution to what could only be a growing problem given the ongoing globalisation of markets and financial transactions. Working through the BIS, in 1996 the Committee on Payment and Settlement Systems issued a comprehensive report on "Settlement risk in foreign exchange transactions". The so-called Allsopp Report assessed the relative merits of delivery-versus-payment (DVP) and payment-versuspayment (PVP) settlements systems and two potential payment/receipt relationships: a guaranteed receipt system (where counterparties are guaranteed that they will receive what they are owed if they fulfil their own settlement obligation) and a guaranteed refund system (where counterparties are guaranteed that their settlement payment will be cancelled or returned if their counterparty fails to pay what they owe). The report did not seem to take a stand on which settlement system would best serve the foreign exchange market. In their words, "While any of the various settlement mechanisms described above could potentially eliminate FX settlement exposures, each has particular strengths and weaknesses that should be considered." ${ }^{10}$

The report did, however, come down clearly in favour of private sector rather than public sector provision of enhanced settlement services. Among the reasons given were the need for ongoing innovation, pressure to provide cost-effective arrangements and private sector methods for controlling risk. Having said this, the

10

The Allsopp Report (1996), p 24. 
report noted the important role for central banks in promoting the safety and soundness of their domestic financial institutions needed to support a multicurrency settlement system. In addition, the Report expressed concern as to the speed of progress and the need for central banks to "induce rapid private sector progress". Given that the Herstatt Bank failure occurred 22 years earlier, the Report noted that "Among the impediments at the individual bank level is a belief held by some banks that the probability of an actual settlement loss is too low to justify the cost of reducing exposures. ${ }^{11}$

Not long after the Allsopp Report was issued, CLS Bank International was founded in 1997 and commenced operations in 2002. CLS Bank is an Edge Act corporation located in New York and is regulated and supervised by the US Federal Reserve. The Federal Reserve also acts as the lead overseer of CLS Bank in a cooperative oversight arrangement with the central banks whose currencies are settled by CLS Bank. CLS Bank is a subsidiary of CLS Group Holdings AG based in Switzerland, which itself is owned as of June 2014 by 76 shareholders representing many of the world's largest financial institutions from 23 countries.

In a little over a decade, CLS Bank has grown to become the "sole global multicurrency settlement system of its kind, offering both liquidity savings and settlement risk mitigation across all major currencies". ${ }^{12}$ In July 2012, the Financial Stability Oversight Council (FSOC), established under the Dodd-Frank Act, designated CLS Bank as a systemically important financial market utility (SIFMU) based on several criteria that attest to the volume of transactions processed by CLS Bank, but also to its critical role in the interconnectedness of the FX market and the costs and risks to financial stability if the ability to rely on PVP settlement for major FX transactions were jeopardised. ${ }^{13}$ Being classified as a SIFMU, CLS Bank is subject to enhanced regulatory oversight by the Federal Reserve Bank and other market regulators.

\section{3.c Basic activities and dimensions of CLS Bank}

CLS Bank, taking its name from a so-called Continuous Linked Settlement process, operates a payment-versus-payment (PVP) settlement service which mitigates settlement risk in the FX transactions of its Settlement Members and their approved customers (known as Third Parties). Although the details of this global operation are complex, the basics of the PVP settlement process are straightforward. ${ }^{14}$ CLS Bank receives detailed information from both counterparties about their FX transaction and then matches the two legs of the transaction scheduled for delivery on date $T$. On the settlement date, $T$, during a window of several hours, CLS Bank receives

11 The Allsopp Report (1996), p 27.

12 Financial Stability Oversight Council (2012, p 157).

13 In total, the FSOC designated eight SIFMUs including the Clearing House Payments Company (CHIPS) and the Depositary Trust Company (DTC).

14 The main text offers a stylised description of a CLS transaction, which is not intended to capture the complexity of all possible outcomes. For instance, of transactions submitted to the CLS, only those that are matched and not rescinded will be settled. CLS Bank generally processes transaction details within seconds or minutes of the trade. In addition, the CLS system multilaterally nets all positions and it is the netted amount on matched trades for which CLS requests payment from each settlement member in each currency on the value date. 
currency A from one counterparty and waits for the receipt of currency B from the second counterparty. Once both legs of the trade have been received and CLS has verified that all details match, CLS releases the funds and pays out to both counterparties. Once settlement has been concluded, it is irrevocable. If counterparty B cannot deliver due to failure, CLS suspends the member and returns the full amount of principal to counterparty $\mathrm{A}$ and avoids settlement risk (or what the Allsopp Report labelled a "guaranteed refund system"). The transaction between $A$ and $B$ is left to settle in some other manner.

At its launch in 2002, CLS Bank settled transactions for seven currencies on behalf of 39 settlement members. At present, there are 17 CLS-eligible currencies including nine of the top 10 currencies by volume from the 2013 Triennial Survey, as well as other currencies with smaller turnover (see Table 3.1). Collectively, these 17 currencies accounted for $93.7 \%$ of global turnover in the 2013 survey although this overstates the potential reach of CLS because both currencies as well as both counterparties in a trade must be CLS-eligible to utilise CLS. As of June 2014, there are 64 settlement members and more than 11,000 third-party members. And while members have the right to settle eligible transactions through $\mathrm{CLS}$, they are under no obligation to do so.

As shown in Graph 3.1, total CLS trading volume across all eligible currency pairs and products has increased substantially since 2007. ${ }^{15}$ The average number of daily transactions hovered in the 300,000-400,000 range in 2007 and expanded to reach 1.25 million per day in the first half of 2013 before declining to about 1 million per day in the first half of 2014. In the interim, the volume of transactions experienced a slight decline associated with the GFC, and also a temporary burst of volume in the first half of 2013 largely as the result of a dramatic jump in JPY trading associated with the change in Japanese monetary policy. ${ }^{16}$ Assuming that the jump in JPY trading is a one-time event, CLS trading volume appears to be stable or slightly rising since 2011.

The average value of CLS trades was roughly $\$ 3.5$ trillion per day in 2007 and then rose to more than $\$ 4$ trillion per day before dropping to about $\$ 2.8$ trillion per day in December 2008. This is a far greater decline than observed in the volume of trades per day during the GFC. Since then, the value of trades has gradually drifted upwards to a little over $\$ 5$ trillion per day in the first half of 2014 . We do not observe as pronounced a rise in the value of trading in the first half of 2013 compared with the spike in transaction volume.

It is critical to note that CLS processes both sides of a trade and includes both sides in its trading value calculation. Therefore to make CLS value data consistent with BIS survey turnover data, we divide the CLS settlement values by two. To begin to illustrate the importance of CLS to the FX market, consider the Triennial Survey estimate for the global value of daily FX trading in April 2013, which was $\$ 5.3$ trillion. CLS reported $\$ 5.0$ trillion as their average daily value settled in April 2013. Dividing the CLS figure by two, in gross terms, CLS would appear to settle around $\$ 2.5 / \$ 5.3=47.2 \%$ of global FX trading. Later in this section, we will provide

15 The data represent matched trades rather than settled trades.

16 The daily volume of USDJPY transactions processed by the CLS Bank jumped from about 100,000 in the last half of 2012 to over 300,000 in the summer of 2013. Data here represent three-month rolling averages, and input volumes, not matched trades. 
additional detail to explore why the resulting implied share of global FX trading that remains subject to settlement risk ( $100 \%-47.2 \%$, or $52.8 \%)$ is an overestimate.

Despite the considerable progress made by CLS Bank, as well as other institutional measures to reduce FX settlement risks, in 2013 the Basel Committee on Banking Supervision (BCBS) concluded that "substantial FX settlement-related risks remain due to the rapid growth in FX trading activities. ${ }^{\prime 17}$ Adding that many banks are prone to underestimate these risks and that their impact can be outsized during periods of market stress, the report called for continued efforts to reduce or manage FX settlement risk. "In particular, the efforts should concentrate on increasing the scope of currencies, products and counterparties that are eligible for settlement through PVP arrangements." ${ }^{18}$ This leads us to examine how much FX settlement risk may remain with special reference to the Asia-Pacific region.

\section{3.d Trading, CLS and PVP in Asia-Pacific (estimates of risk mitigation)}

In this section, we offer estimates on the availability and utilisation of CLS and other PVP settlement systems in Asia-Pacific. One way to benchmark the CLS footprint in the Asia-Pacific region is based on the turnover data in the 2013 BIS survey. In Table 3.2 , the data indicate that 13 Asia-Pacific countries account for slightly over $21 \%$ of all global FX turnover whether we measure in terms of trading location or the currencies traded. By several measures, Asia-Pacific countries appear to be well represented in the CLS community. In terms of the governance of CLS, of the 76 shareholders of CLS Group Holdings, 15 are from the Asia-Pacific region. CLS shareholders are headquartered in 23 countries including five in the Asia-Pacific region. In term of settlement, there are six Asia-Pacific currencies among the 17 CLS-enabled currencies. There are 64 settlement members including 18 from Asia-Pacific. And finally, CLS settlement services extend to a large number of thirdparty members including more than 770 from the Asia-Pacific region or about $6.7 \%$ of the total. By comparison, three countries (the United States, United Kingdom and Luxembourg) tally more than 7,000 third-party members. These countries are home to many investment management companies who may elect to establish third-party membership for individual funds, each of which may stand as separate legal entities. Apart from third-party membership, in a general sense, the data suggest that AsiaPacific countries have a presence in CLS on a scale that reflects their activity in the global FX market.

In addition, various Asia-Pacific countries have developed PVP systems, or alternative risk mitigation measures to address delivery risk in their home currencies that are not presently CLS-enabled. The Philippines uses a real-time gross settlements (RTGS) system with PVP for Philippine peso vs US dollar trades. In 2006, Malaysia instituted the first cross-border PVP link in the region with the Hong Kong Monetary Authority (HKMA) for settling ringgit-US dollar trades. In 2010, Indonesia established a similar arrangement with the HKMA for settling rupiah-US dollar trades. The Bank of Thailand is exploring a link with the HKMA to enable settlement

17 Basel Committee on Banking Supervision, "Supervisory guidance for managing risks associated with the settlement of foreign exchange transactions", February 2013.

18

BCBS $(2013$, p 3). 
of baht-US dollar trades. ${ }^{19}$ Notably, once an HKMA link is established, settling trades against the EUR, HKD, and CNY would become feasible. And even though India presently does not have a PVP system or a link to one in place, the Reserve Bank of India relies on a detailed system of margin, lines of credit and penalties in the event of a shortfall to reduce settlement risk in rupee-US dollar trades. ${ }^{20}$

To examine the potential use of CLS and PVP more closely, we obtained disaggregated turnover data from the 2013 BIS Survey for a 40 x 40 currency matrix including all 17 CLS-enabled currencies and 23 other currencies. A diagram of the matrix is shown in Graph 3.2. Currency combinations with positive turnover data are indicated by the numeral "1." Rows and columns are arranged to list the non-AsiaPacific currencies first (11 CLS-enabled currencies followed by 16 others) and the Asia-Pacific currencies next (six CLS-enabled followed by seven others). Only the currency pairs in regions $\mathrm{X} 1, \mathrm{X} 3$ and $\mathrm{X} 8$ are $\mathrm{CLS}$-eligible. Other currency pairs (USD/INR, USD/MYR and USD/PHP) that offer PVP settlement are marked separately. Out of a maximum of 780 unique cross-rates in the matrix, positive turnover data are available for 273 pairs ranging from $\$ 1.288$ trillion per day for the EUR-USD pair to very small turnover numbers for the more obscure pairs. The disaggregated data allow us to develop more refined estimates of the share of trading that may benefit from risk mitigation through PVP settlement in different segments of the FX market. Tables 3.3 and 3.4 show a sample of these results.

On a global level, turnover among all pairs of the $17 \mathrm{CLS}$ currencies measures $90.46 \%$ of global turnover. This estimate is slightly smaller than the $93.7 \%$ estimate given earlier based on the sum of trading in all 17 CLS currencies, because it excludes trades involving one non-CLS currency that cannot be settled through CLS Bank. The data show that slightly greater turnover, $92.93 \%$, is CLS-eligible among 11 Asia-Pacific currencies than among the 27 non-Asia-Pacific currencies where the share is $90.93 \%$. One reason for this difference is the vehicle currency role played by the USD against many non-CLS currencies and as well as FX turnover between the EUR, GBP, CHF and others against many non-CLS currencies.

Because of greater time-zone differences, Herstatt risk can be greater between Asia-Pacific currencies and currencies in Europe and North America. Therefore, turnover in these pairs may hold special interest. The BIS data suggest that, for trades between Asia-Pacific currencies and all others, a somewhat smaller share of turnover (89.79\%) is in CLS currencies compared with $90.43 \%$ for trades between non-Asia-Pacific currencies and all others. ${ }^{21}$ However, taking into account that IDR, MYR and PHP trades against the USD can make use of separate PVP arrangements, Asia-Pacific currencies appear to have a larger share of turnover (92.56\%) where risk mitigation is available compared with the share (91.59\%) for non-Asia-Pacific currencies.

19 "Payment Systems Report", Bank of Thailand, 2012, p 25. The link became operational on 28 July 2014.

20 See Committee on Payment and Settlement Systems (2011, p 181). In addition, the Clearing Corporation of India Limited (CCIL) is a third-party member of CLS that offers settlement services in CLS-enabled currencies to participating banks (fourth parties) as a settlement aggregator. Ibid at p 183.

${ }^{21}$ The share is $89.70 \%$ for Asia-Pacific currencies versus only non-Asia-Pacific, or $\mathrm{X} 3 /(\mathrm{X} 3+\mathrm{X} 4+\mathrm{X} 6+\mathrm{X} 7)$ in Graph 3.2. 
Overall the BIS data confirm that a large share of global FX turnover flows through currency pairs that are eligible for risk mitigation through CLS or other PVP arrangements. The data also suggest that the share eligible for risk mitigation is slightly larger for trades among Asia-Pacific currency pairs, or pairs involving an Asia-Pacific currency compared with the analogous figures for non-Asia-Pacific currencies. Trades in IDR, MYR and PHP versus the USD account for more than $28 \%$ of turnover for non-CLS currencies in Asia-Pacific versus currencies in later time zones. Thus, the separate PVP arrangements by the central banks of Indonesia, Malaysia and the Philippines could, if widely used, play an important role in supplementing the risk mitigation services offered by CLS Bank.

\section{3.e Risks that remain despite CLS and other PVP settlement systems}

The figures in Table 3.3 are estimates of the upper bound on the percentage of FX turnover that could be settled through CLS or other PVP settlement systems. However, it is difficult to make the linkage between these estimates and (a) the share of turnover that actually utilises risk-mitigating settlement, and (b) the share of turnover that remains subject to settlement risk. Simply because trades could be settled using a risk-mitigating system does not mean that counterparties can or will take the option to use it. And, perhaps surprisingly, even if a trade does not use CLS or another PVP system, the trade may not be subject to settlement risk.

The first part of this explanation is apparent. Only counterparties who are settlement members or third-party members can exercise the option to settle through CLS Bank. ${ }^{22}$ However, not utilising CLS need not imply that a trade is subject to settlement risk. Consider a EURUSD trade between Bank $A$ and Company B. If $B$ maintains its EUR and USD accounts within Bank $A$, there is no need for the bank to transmit funds from one bank to another (so called "on-us" settlement). Alternatively, consider a USDJPY forward contract between Bank A and Hedge Fund $C$. The bank could be aware that the hedge fund intends to cash settle the forward contract and not take delivery. And so there is no need for PVP settlement, and also no settlement risk. ${ }^{23}$ In the same fashion, trades between two non-CLS-eligible currencies would not be subject to settlement risk if they were settled internally within a single bank, or subject to cash settlement rather than delivery.

In 2013, CLS Bank started its own survey to assess more accurately the share of FX turnover that members route through CLS and the extent to which other settlement methods are utilised. ${ }^{24}$ While a final version of the survey has not been released, it appears based on a preliminary draft of the report that close to $55 \%$ of trading activity in CLS-eligible currencies flows through $\mathrm{CLS}{ }^{25}$ Most of the remainder benefits from risk mitigation through on-us settlement or bilateral

22 The central banks in Indonesia, Malaysia and the Philippines have their own systems for vetting access to their PVP systems.

23 Credit risk between the counterparties still remains. In the forward contract example, the counterparty could elect to cash settle regardless of whether the contract serves a speculative or hedging purpose.

24 See Clark, "CLS Expansion will be key to EM currency growth", FX Week, 19 July 2013.

25 We thank Dino Kos and Rachael Hoey of CLS for allowing us to review a preliminary version of the report. 
netting, leaving a little over $10 \%$ subject to gross non-PVP settlement. ${ }^{26}$ In this case, $10 \%$ of roughly $\$ 4.5$ trillion, or $\$ 450$ billion, in daily trading leaves a large potential exposure. For non-CLS currencies, clearly none settle through CLS but, as we have seen, a small amount settles through other PVP systems, much more settles on-us, and close to half benefits from bilateral netting. But this still leaves more than one third of non-CLS currencies to settle through a gross non-PVP process. In this case, one third of roughly $\$ 500$ billion, or $\$ 167$ billion, in daily trading involving non-CLS currencies also represents a substantial potential exposure.

Combining these two figures we arrive at $\$ 617$ billion as a rough estimate of daily FX turnover subject to settlement risk through a non-PVP process. This estimate excludes daily turnover in currency swaps and FX options, estimated at $\$ 390$ billion in 2013 , that are not CLS-eligible products. ${ }^{27}$ In total, perhaps as much as $\$ 1,000$ billion in daily FX turnover may be settled at present without the benefit of some type of risk mitigation.

Looking into where settlement risk remains, among the non-CLS currencies, our own analysis based on Graph 3.2 reveals that among currency pairs with an AsiaPacific component the USD/CNY rate shows the highest turnover at $\$ 112.68$ billion/day. And for non-Asia-Pacific pairs, the USD/RUB is the largest at almost $\$ 79$ billion/day. Early in 2014 , press reports predicted that the rouble was likely to become CLS-eligible by year-end. ${ }^{28}$ And in 2012, China indicated that it was in the process of developing an advanced payment system that would support PVP of the renminbi against foreign currencies. ${ }^{29}$ In a recent interview, David Puth, the Chief Executive Officer of CLS, was quoted as saying that discussions with the jurisdictions of number of other currencies were "well under way". ${ }^{30}$ So indications are that additional currencies are under active consideration for the CLS system. ${ }^{31}$

Despite the progress to date and the likely progress ahead, it is important to keep in mind a succinct comparison offered by the Allsopp Report in 1996. The CLS Bank has been engineered to offer a "guaranteed refund system" rather than a "guaranteed receipt system". Thus, in the event that a CLS third-party member fails (eg Lehman Brothers), the trade may be rescinded in advance (leaving the counterparty to make other settlement arrangements). Or, if the trade is not

26 Presumably some portion of this activity is forward contracts that cash settle. While the initial setup costs for CLS membership could deter some new members, the marginal cost of using CLS is very small. (Banks averse to the initial costs of CLS membership also have the option to become thirdparty members). In its interim financial report for the six months ending 30 June 2013, CLS reported revenues of $£ 86.8$ million. With more than 1.25 million matched trades per day, revenue to CLS is less than $\$ 1.00$ per trade.

27 Currency swaps and non-exchange-traded FX options will be subject to risk mitigation through CCP arrangements as required by the Dodd-Frank Act. Those regulations are in the process of being drafted.

28 See E Szalay, "CLS set to add Russian ruble in November, source says", FX Week, 12 February 2014. This has since been deferred.

29 See Committee on Payment and Settlement Systems, "Payment, clearing and settlement systems in China", 2012, p 44.

30 See K Alys, "Spotlight on: David Puth, CLS", FX Week, 22 October 2012. Brazil, Chile, Thailand, Russia and China were mentioned in the article.

31 In its "Report on Payment Systems, 2013", the central bank of Hungary discusses a letter of intent to join CLS, and includes estimates of the FX settlement risk exposure in Hungarian banks. 
rescinded in time, the settlement member responsible for the third party will be left to meet their CLS obligations. A guaranteed receipt system, such as a regulated futures exchange, would have detailed margin requirements and function like a CCP, which is not the case for CLS Bank.

Finally, as the Allsopp Report also anticipated, a multicurrency settlement mechanism (such as CLS) might also create a new source of systemic risk despite its risk-reducing potential. As the Report phrased it: "a disruption in the settlement of one currency could disrupt the settlement of all other linked currencies. ... The possibility of not receiving the currencies they purchased on time could lead participants in guaranteed refund systems to hold back their payments at times of market stress, thereby increasing the total number of failed settlements" ( $p 25$ ). In naming the CLS Bank as a systemically important financial market utility, the FSOC built on many of the same points. Their report $(2012, \mathrm{p} 157)$ noted in part that the "...CLS Bank's expansion will reduce overall risk but also concentrate the risk associated with a potential disruption to or failure of CLS Bank."

\section{FX market behaviour during periods of high volatility}

Institutional safeguards are likely to be most important during times of rising and high volatility in markets. In the following we briefly review the movement of exchange rates and metrics of FX market liquidity in Asia-Pacific over the past 10-15 years, paying particular attention to market characteristics during periods of high volatility, most notably the global financial crisis of 2008-09 and the "taper tantrum" of 2013. The latter episode of volatility occurred after the Federal Reserve indicated its intention to begin "tapering" the degree of quantitative easing, conditional on economic stabilisation proceeding as expected. We also present some event study analysis to assess the impacts of the tapering announcements in 2013.

\section{4.a Literature on FX market impacts of the GFC and "taper tantrum"}

A characteristic of the global financial crisis was the substantial appreciation of the US dollar when the crisis deepened, even in response to negative US-specific macroeconomic shocks which in normal circumstances would have led to US dollar depreciation (Fratzcher (2009)). Not surprisingly, fundamentals played a role in determining which countries' currencies depreciated the most in response to financial stability shocks. In particular, those countries with large current account deficits and fewer FX reserves experienced significantly larger depreciations against the US dollar. However, exposure to the risk appetite of US investors was another important factor. The currencies of countries in which US investors held relatively large portfolio investments consistently depreciated more. Clearly, financial openness and integration increased the vulnerability of countries to external shocks.

Another striking feature in FX markets during the global financial crisis was large and persistent deviations in major markets from covered interest rate parity in major currency pairs. Baba and Packer (2009b) documented that, both in the GFC's early stages in 2007 and even more so in 2008-09, covered interest rate parity did not hold across many currencies pairs. For the most part, these deviations reflected 
a shortage of US dollar funding in global markets during the crisis (McGuire and von Peter (2009)).

Another period of volatility in FX markets followed heightened expectations of changes to US monetary policy in 2013 and early 2014. In particular, big depreciations in a large number of emerging market currencies were associated with tapering announcements by Federal Reserve Chair Ben Bernanke (Aizenman et al (2014)). The impact of the tapering news differed according to country fundamentals, but in a manner different from that noted for the GFC: ie the currencies of countries with current account surpluses, high international reserves and low debt burdens depreciated more than other currencies. The authors interpret this result as consistent with fragile economies having built up less exposure to financial flows, or "hot money" during earlier periods of relatively high rates in EMEs (and quantitative easing by the Federal Reserve). That said, while the immediate response at the daily frequency was most evident in the exchange rates of more robust economies, by the end of 2013, the currencies of fragile economies had experienced the most depreciation, as markets eventually reflected the adverse global implications of higher rates.

Other studies focusing on the exchange rate depreciation over the entire summer of 2013 also point towards a correlation of local currency depreciation and financial fragility. Eichengreen and Gupta (2013) show a positive relation of depreciation with deterioration of the current account and appreciation of real exchange rates during the earlier three years. The authors also document that the currencies of countries with larger financial markets depreciated more between April and September 2013, indicative that "large markets are more prone to the effects of liquidity retrenchment." On the other hand, more conventional measures of vulnerability such as public debt and budget deficits had little relation to the degree of currency depreciation during the taper tantrum.

\section{4.b FX rate movements}

In the following section, we review the bilateral exchange rates of the 12 Asia-Pacific currencies examined in Part 2 versus the US dollar. In the left-hand panels of Annex Graph 1, dramatic depreciation versus the US dollar is observed across a large cross-section of currencies during the peak of the financial crisis in 2008 , the most for the Australian and New Zealand dollar at $60 \%$, and $25-50 \%$ for the Indian rupee, the Indonesian rupiah, the Korean won and the Philippine peso. Somewhat more modest depreciations were observed for the Malaysian ringgit, the Thai baht, and Singapore dollar. As the Chinese renminbi does not float freely against the US dollar, it was rather unaffected during the crisis. Moves in the Hong Kong dollar, which runs a currency board, were also miniscule by comparison. The Japanese yen, often a safe haven currency, depreciated $10 \%$ in early 2008 , but otherwise tended to appreciate against the dollar over the period.

By contrast, the depreciation pressure during the 2013 episode of turbulence was much more limited for most Asia-Pacific currencies (Annex Graph 1, right-hand panels). For India and Indonesia, there was indeed depreciation of their currencies on the scale that had been seen during the GFC, by around $20-30 \%$ for the two currencies from the high to the lows of 2013. But for the bulk of currencies, including those of Australia, Korea, Malaysia, New Zealand, the Philippines and Thailand, depreciation was much less, and in regimes which allow much less degree 
of currency flexibility versus the dollar, such as China and Hong Kong, significant impacts were not detected.

Table 4.1 reports FX rate changes and presents formal tests of significance with regard to the announcement effects of three major Federal Reserve announcements, suggestive either of future tapering or confirming the tapering of its asset purchase programme, on 22 May, 19 June and 18 December $2013 .{ }^{32}$ Indeed, all 12 of the currencies depreciated against the dollar on a net basis on the day after the tapering announcements (nine significantly so in a statistical sense), with nine of the 12 currencies having depreciated on each of the three days.

Interestingly, many high-turnover currencies, as measured by the triennial survey, depreciated the most sharply, with statistically significant depreciations ranging in aggregate on tapering announcement dates from lows of $0.03 \%$ and $0.24 \%$ (the HKD and RMB) to highs of $4.3 \%, 3.4 \%$ and $3.3 \%$ for the NZD, KRW and AUD, respectively. Currencies of seven out of 12 jurisdictions experienced a greater than $2.3 \%$ depreciation versus the US dollar on aggregate over those three days. The Indonesian rupee and Indian rupiah, which had by far the largest depreciation during the seven months covering the three announcements (May 22-December 18), had rather small reactions $(-1.9 \%$ and $-0.6 \%)$ in total - for the three days after the actual key announcements themselves.

\section{4.c Measures of FX market liquidity}

Bid-ask spreads. The relative bid-ask spread is a common measure used to assess liquidity in FX markets (Karnaukh et al (2014)). Here we use daily bid and ask and mid-quote prices from Datastream Thomson Reuters. With similar data, Rime and Schrimpf (2013) document a decline in average bid-ask spread for currencies of emerging market economies and, at least by this metric, convergence in liquidity conditions of EM currencies to those of advanced countries.

Indeed, for many of the EM currencies in Asia-Pacific that we are examining, average bid spreads show a trend decline in reported relative bid-ask spreads over the past 15 years (with the exception of the Malaysian ringgit, where the data are available only from 2004 and started at relatively low levels) (Annex Graph 2, lefthand panels). Reported spreads for the advanced economy currencies of the Japanese yen, Australian and New Zealand dollars showed some decline between in the early 2000s, but have been mostly stable since 2004. Around the global financial crisis, it was principally the Indonesian rupiah that shows a rise in reported spreads that was notable over the 15 year time frame (to nearly $2 \%$, although it should be acknowledged that similarly large rises were apparent in 2004 and 2006 as well.)

Rises in bid-ask spreads over the later period of market turbulence in 2013 were principally in Indonesia and Philippines (Annex Graph 2, right-hand panels).

32 Nearly all of the daily series are all taken at the Asia close (NDF series were taken from the London close), while the FOMC announcements or subsequent press conferences all happened in the US afternoon, or after the Asia (or European) close. Therefore, information from the Federal Reserve announcements on day $t$ should be captured in the difference between the date $t+1$ and $t$ rates. Estimates were roughly similar (though less precise) when the difference between day $t+2$ and day $t$ was considered. Higher-frequency data, which would allow one to abstract from other information that may have been released in the one-day window, were not available to us in this study. 
For the rupiah, spreads rose by a factor of nearly four, from 10 basis points to around 40 basis points, while Philippine peso spreads saw a smaller increase of roughly three times to 10 basis points over the later period. Event study evidence does not suggest an outside reaction of spreads after the specific tapering announcements, however, in either of these or the other currencies under investigation (Table 4.2).

Implied volatilities. Implied volatilities, which capture the cost of insurance against sharp moves in exchange rates, rose quite dramatically during the GFC in 2008 for all of the currencies examined (Annex Graph 3, left-hand panels). Implied volatilities also rose during the 2013 period, particularly in the second and third quarters, but not to the peaks of the GFC (Annex Graph 3, right-hand panels). Event study evidence indicates that implied volatilities rose significantly after at least one of the tapering announcements in nine out of the 12 currencies (Table 4.3). In contrast to the depreciation of exchange rates, in which a number of the sharpest moves were concentrated in the advanced economy currencies with high turnover (AUD, NZD), the most pronounced rises in implied volatility tended to be currencies of emerging Asia, in particular the Indonesian rupiah and Philippine peso $(3.1 \%$ and $2.9 \%$, respectively). However, currencies in regimes which allow less flexibility versus the dollar - the Chinese renminbi and Hong Kong dollar - did not have a significant rises in implied volatility.

Realised volatilities. Realised volatilities have been found to correlate well with other metrics of liquidity, and have the advantage of being available over longer time periods and for more currencies (Karnaukh et al (2014)). Annex Graph 4 (left-hand panels) reports time series for the monthly averages of the absolute value of daily changes to interest. The volatility of most currencies against the dollar hit their peak during the GFC but, by this measure, the Indian rupee clearly suffered its most illiquid period during the 2013-14 bout of market turbulence, with realised volatilities rising well above the 2008-09 period. The Philippine peso, Thai baht and Singapore dollar's realised volatilities also rose considerably in 2013, particularly in the second and third quarters (Annex Graph 4, right-hand panels).

Deviations from covered interest parity. It has been well established in a number of papers (eg Baba and Packer (2009a, 2009b)) that covered interest parity did not hold in a number of markets around the time of the financial crisis in 2008-09. In fact, reflecting well known US dollar shortages, the Federal Reserve arranged swap lines with numerous other central banks to counteract dollar shortages, and deviations subsequently declined as confidence returned. Deviations increased again with the European sovereign crisis, but returned to close to precrisis levels for the most part. Some Asia-Pacific currencies also showed deviations from CIP versus the dollar during the crisis (Annex Graph 5), which was attributed more to tight funding conditions than to counterparty risk (Genberg et al (2011)).

However, when we examine the currencies of the Asia that showed significant positive deviations from CIP during the crisis, while there was a statistically significant announcement effect (in aggregate) for one currency (KRW), it was shortlived and very small relative what was observed in 2008-09 (Table 4.4 and Annex Graph 5). The other currencies (JPY, PHP, IDR) that had seen major deviations from CIP during the global financial crisis did not show any such behaviour during the taper tantrum period (Annex Graph 5 and Table 4.4). It would appear that the dollar shortages which characterised the earlier period, when the stability of the entire 
global financial system was at stake, were not a factor in the region during the more recent period of volatility.

Forward premium gap. Forward FX rates from onshore markets can at times mislead. In many currency markets, differences between deliverable forward and (offshore) non-deliverable forward (NDF) rates can emerge, reflecting limits to arbitrage, particularly in stressed market conditions (McCauley et al (2014)).

Indeed, the deliverable forward-NDF premia widened sharply for a number of Asia-Pacific currencies during the global financial crisis, when the offshore NDF rate depreciated by more than the onshore forward rate (represented by negative differentials for five currencies, shown in Annex Graph 6, left-hand panels). Though not by as much, the differentials also widened for certain currencies at points during the May-December 2013 taper tantrum period (Annex Graph 6, right-hand panels). Particularly affected were differentials in the Indonesian rupiah and Philippine peso, falling below $-4 \%$ and $-1 \%$ at their troughs, respectively, with statistically significant falls in the differential evident around the key announcement dates of the taper tantrum (Table 4.5). The forward premia of the Indian rupee also fell below $-1 \%$ during the taper tantrum period (though not in response to announcements), but large offshore-onshore differentials were not as evident for the Chinese renminbi and Korean won. The coincidence of (forward) currency depreciation in the NDF market with a widening of negative premium is consistent with the stylised fact found in other studies that the offshore NDF market tends to lead the deliverable market in times of market stress.

It is also worthy of note that daily turnover - for which data are available for the Indonesia rupiah, Indian rupee and Philippine peso during 2013 - increased sharply in the days after each of the three tapering announcements in the case of the Indonesia rupiah and Philippine peso. Excepting China, these are the two currencies among the group in Table 4.5 that have the largest ratio of trading taking place offshore; these are also the currencies where the offshore-onshore forward differentials responded the most to the tapering announcements. An increase in volume at times of market turbulence is consistent with both turnover and prices reacting to the arrival of new public information, as suggested in the findings of Galati (2000).

\section{4.d Market indices}

In the following section, we focus on a particular FX trade that is common both among FX investors in the Asia-Pacific, and in currencies of Asia-Pacific jurisdictions: namely, the carry trade. The evidence shows that carry trade investors earned abnormal losses during the days after the announcements of the Federal Reserve's intention to taper asset purchases. Specifically, broad carry trade indices based on G10 currencies and those based on EME currencies on net lost $2.3 \%$ and $1.6 \%$, respectively, in the days immediately following the three major taper announcements mentioned earlier, often as much as or more than the individual vulnerable currencies themselves. We shall proceed to examine the stability features of the carry trade for FX markets in the Asia-Pacific. 


\section{Carry trades in the Asia-Pacific Region and crowdedness}

Carry trades have attracted the attention of investment professionals, researchers and government policymakers throughout most of the modern floating exchange rate period. Carry trades in the FX market take long positions in one or more highyielding (target) currencies financed by short positions in one or more low-yielding (funding) currencies. The strategy is profitable when the target currency does not depreciate by more than the interest differential. Indeed, it is not uncommon for the target currency to appreciate, thereby producing an exchange rate gain for the investor in addition to the yield differential. There is strong evidence that currency carry trades have been profitable for the last 20 years or more. ${ }^{33}$ Nevertheless, questions remain as to whether carry trade profits when calculated are largely offset by trading costs, or whether they are simply a reasonable compensation for attendant risks, or instead represent real economic profits in excess of associated risks. $^{34}$

The carry trade is of special interest for the Asia-Pacific region for several reasons. First, for most of the last 20 years, the region has been home to one traditional funding currency (JPY) and several traditional target currencies (AUD, NZD, INR and other EM currencies). Thus, the region may be prone to the macroeconomic and financial market side effects traditionally associated with the building-up and unwinding of carry trade strategies (eg see Cucuru, Vega and Hoek (2010)). Second, at least two rapid unwinds of carry trades have involved Asia-Pacific currencies. In 1998, the JPY (even at that time an important funding currency), depreciated to nearly 146 USDJPY in August but ended the year around 114 . Included in that move was a $14 \%$ appreciation over the space of two days, October $6-8$, the yen's largest two-day move since the beginning of the float in February 1973. In a similar vein, but over a longer time horizon, from 2000 until the summer of 2008, the JPY (still a funding currency) depreciated against the AUD from roughly 60 AUDJPY to over 107 AUDJPY producing substantial gains for carry traders who were long the AUD. However, after the Lehman Brothers bankruptcy in September 2008, carry traders unwound their positions quickly. The AUD dropped below 60 AUDJPY by late October 2008, resulting in losses for carry traders unable to close out their positions fast enough.

Recently some analysts have pointed to the performance of the CNY carry trade against the USD as a funding currency, which has raised concerns in some quarters that another large unwind could be looming. ${ }^{35}$ As noted in the previous section, the prospects of earlier or faster than expected Fed tapering contributed to greater volatility in many FX markets; this is in turn may have resulted in a faster and more

33 See, for example, Gyntelberg and Schrimpf (2011).

34 Burnside et al (2006) argue that market frictions such as bid-ask spreads and price pressure that are an increasing function of order size are sufficient to greatly reduce the profitability of carry trades and push the marginal Sharpe ratio toward zero. Research by Burnside et al (2010), Brunnermeier, Nagel and Pedersen (2009) and others supports the view that carry trade profits reflect a peso problem or crash risk premium. Mancini, Ranaldo and Wrampelmeyer (2013) find evidence of systematic variation in FX market liquidity that could contribute to carry trade returns. Bilson (1981) produced the first rigorous, out-of-sample test of a carry trading strategy and concluded that the performance was too good to be consistent with credible risk premiums.

35 See B Hafeez (2013). 
damaging unwind of carry positions. Risk can be compounded because carry positions are easily levered and the overall size of aggregate positions is difficult to judge beforehand. Beyond the risks that fall on private investors, Curcuru, Vega and Hoek (2010) point out that risks associated with excessive exchange rate and asset price volatility as well as increased stress on the banking system stemming from loan defaults impact the broader economy, which makes the carry trade a concern for financial regulators and policymakers.

\section{5.a Carry trade returns and risks}

By construction, a carry trade targets investment in a high-interest rate currency financed by borrowing in a low-interest rate currency. When the high interest rate reflects a scarcity of capital and high real rate of return and the low interest rate reflects an abundance of capital and low real rate of return, carry trades serve a useful economic purpose in helping to equilibrate rates of return and promote a more efficient allocation of capital. On the other hand, when only a nominal interest rate difference is observed, uncovered interest parity (UIP) implies that there is no incentive for capital flows because depreciation of the high-interest rate currency will fully offset the interest differential. In practice, most analysts base carry trade signals on the nominal interest rate differential, and the change in this as well as the exchange rate will determine the profitability of the carry trade in the investor's base currency.

Graph 5.1 illustrates the cumulative return on a simple carry trade strategy with equally weighted long positions in the three highest-yielding G-10 currencies financed by equally weighted short positions in three lowest-yielding G10 currencies and held over the 1989-2013 period. Over the 24-year sample period, this stylised strategy would have produced an average annual excess return (above the risk-free rate) of $5.9 \%$ with annualised volatility of $9.3 \%$ which implies a Sharpe ratio exceeding 0.6. ${ }^{36}$ Graph 5.2 shows the cumulative return for an analogous carry trading strategy for a portfolio of EM currencies over a shorter sample period, 2001-13. Rosenberg (2014) notes that the sample period does not cover an earlier period when periodic currency crises hit EM countries, but that it could fairly represent a period when global investors took greater awareness of EM carry trades. Over the 13-year sample period, this EM carry trade strategy would have produced an average annual excess return of $10.7 \%$ with annualised volatility of $11.4 \%$, which implies a Sharpe ratio of 1.1. The results are striking but Rosenberg (2014) cautions that insufficient liquidity in various EM currencies as well as capital flow restrictions and regulations might have limited investor's ability to undertake these trades in sizeable amounts.

Both Graphs 5.1 and 5.2 illustrate a pattern of cumulative returns that generally moves upwards over time, but is punctuated occasionally by short periods of large losses. ${ }^{37}$ Following Brunnermeier, Nagel and Pedersen (2009), it can be useful to briefly sketch the macroeconomic setting that enables this pattern of returns to

36 For comparison, the Sharpe ratio for a buy-and-hold strategy on the S\&P 500 stock index has averaged about 0.3 .

37 The imagery sometimes used is that carry trades are like "picking up nickels in front of a steam roller", or that carry trades "go up by the stairs, and down by the elevator." 
develop. To begin, once an interest differential is observed, investors will not react immediately. Contrary to UIP theory, carry trade investors are exposed to a variety of risks, such as exchange rate risk and liquidity risk. Given risk aversion, these factors are likely to retard the rate at which investors pursue carry trades and the ultimate size of their positions. Over time, as carry trade profits are realised, other investors may be attracted and early investors may have had both the inclination and time to arrange financing to leverage their positions. Even if policymakers observe carry trade positions mounting, they may be reluctant to adjust interest rates (presumably set to meet domestic economic objectives) that would reduce the carry or affect exchange rate expectations. And so the cycle of carry favouring the target currency and greater investor confidence continues. At some point, a shock occurs - possibly a change in the expected path of interest rates, or of exchange rates, or in investor access to credit needed to roll over their positions - that leads some investors to begin unwinding their positions. Depending on the nature of the shock, the more apparent the shock is and the greater its impact on more investors, the more likely it is that many investors will attempt to unwind more of their positions at the same time, thus precipitating a rush for the exits, a large drop in the exchange rate, and sudden large losses for carry trade investors.

The Australian dollar-Japanese yen experience from 2002-08 provides a textbook illustration of both the time pattern of carry trade returns and their distribution. As shown in Graph 5.3a, the three-month nominal interest rate differential between AUD and JPY hovered around $5 \%$ at the start of this period before moving higher. Even on a risk-adjusted basis (see Graph 5.3b), carry returns were significant and also trended upward over the period. Risk reversal prices, representing the price of out-of-the-money calls on JPY versus similar calls on AUD, were positive, indicating that market expectations favoured a yen appreciation. Nevertheless, the AUD appreciated gradually over the period until the summer of 2007. The AUDJPY dropped from 103 in mid-July 2008 to about 85 just prior to the Lehman Brothers bankruptcy on September 15. Within six weeks, the rate had fallen below 60 AUDJPY.

\section{5.b Evidence of carry trade activity and warning signs}

Related literature. While there is abundant evidence on the historic patterns of carry trade risk and return, there is less agreement on how sizeable and important carry trade activity may be in financial markets, or how to measure it. Galati, Heath and McGuire (2007) examine a number of indicators to gauge the magnitude of carry trade activity. Data on bank positions and cross-border flows in known funding and target currencies are consistent with greater activity in these currencies. However, the authors acknowledge that it is difficult to determine whether these positions are explicitly related to carry trades.

Tracking the net open positions of non-commercial traders in currency futures contracts is another approach in wide use by professional analysts. This approach assumes that commercial traders are predominantly hedgers while non-commercial traders reflect the speculative component of the market. However, while a futures exchange can easily classify traders as commercial or non-commercial, it is possible that some commercial accounts use futures contracts to engage in currency speculation. In addition, the currency futures market is a small share of global FX trading and so an indicator based on futures contracts may not be representative of the overall market. Acknowledging these limitations, Galati, Heath and McGuire 
(2007) provide evidence that net long non-commercial open positions in several target currencies tended to build along with risk-adjusted returns on carry, and that funding currencies displayed a complementary net short open position. The authors offer additional supportive evidence, based on turnover data in the broader FX market, that shows a positive correlation between turnover and the carry-to-risk ratio for target currencies.

In a related paper, Curcuru, Vega and Hoek (2010) propose a more direct approach for gauging the importance of carry trades based on exchange-traded funds (ETFs) and exchange-traded notes (ETNs) whose returns are directly linked to carry trade strategies. By itself, the introduction of securities linked to carry trades demonstrates the wider interest in and greater availability of financial products linked to currency carry trades. The authors note that the volume of outstanding shares for one ETF tended to grow along with the carry-to-risk ratio but that, as products intended for retail investors, ETFs and ETNs might not be representative of the larger institutional market. Based on this information, together with data for net open positions of non-commercial traders in currency futures contracts as well as BIS data and US Treasury International Capital (TIC) data on cross-border capital flows, the authors are not able to find "convincing evidence that carry trade strategies were adopted on a widespread and substantial basis" over the period leading up to and just subsequent to the GFC.

In his survey of carry trading, Rosenberg (2014) lends support to this view with the possible explanation that FX managers "appear to place a great deal more emphasis on risk management than on return enhancement, so much so that they appear to prefer leaving money on the table rather than pursuing risky strategies such as FX carry trades that could leave their portfolios exposed to potentially large downside moves." To support this interpretation, Rosenberg observes that an index of FX fund manager performance is weakly correlated to carry returns and that the returns for FX managers on the whole display much less volatility and lack the characteristic left skew of carry trade returns more generally.

Carry returns and style analysis: methodology. Carry-trade investments represent only one of a number of different currency investment strategies. In the following we review a method for examining the prevalence of carry trading strategies which is based upon comparing the pattern of returns for carry with the pattern of returns for professional investors, while taking into account the possibility of alternative investment "styles".

The approach, developed in a series of papers by Pojarliev and Levich (2008, 2010, 2011), relies on a simple factor model that expresses returns on a currency fund as a linear function of a several indices that serve as proxies for currency investment strategies such as carry, trend following/momentum investing, and value. Each of these indices, also known as style factors, represents an investable index that follows a well-specified, dynamic strategy. Analogous to the carry trade which owns high-yielding currencies financed by short positions in low-yielding currencies, the trend strategy owns currencies with a positive trend financed by short positions in currencies with a negative trend, and the value strategy owns the most undervalued currencies financed by short positions in the most overvalued currencies. Pojarliev and Levich use a currency volatility index as a fourth factor to 
capture the overall risk level. The model has the form:

$$
R_{t}=\alpha+\sum_{i} \beta_{i} F_{i, t}+\varepsilon_{t}
$$

where

$R$ is the excess return generated by the currency manager, defined as the total return $\left(R_{t}^{*}\right)$ less the periodic risk-free rate $\left(R_{F, t}\right)$

$\alpha$ is a measure of active manager skill,

$F$ is a beta factor, that requires a systematic risk premium in the market,

$\beta$ is a coefficient or factor loading that measures the sensitivity of the manager's returns to the factor, and

$\varepsilon$ is a random error term.

Do "global macro" investors pursue carry? While the dependent variable in this analysis is usually the time series of returns of funds or groups of funds that specialise in currency investments, the group that we first consider below are socalled global macro fund managers, many of whom make explicit reference to currency strategies in their stated investment mandates. Global macro funds have the benefit of representing a larger pool of capital, nearly $\$ 200$ billion or a little over $8 \%$ of all assets under management in the hedge fund industry in 2014 according to Hedge Fund Research. On the other hand, global macro funds pursue a variety of strategies that are not entirely pure currency plays, and so their connection to carry and other currency strategies may be more likely to fluctuate over time.

To explore the possible reliance on currency carry trades by global macro funds, we regress the returns on the HFRI Macro Total Index against the DB Carry Index using monthly data over the period January 2000-August 2014. We estimate a set of rolling regressions based on 12, 18 and 24 months and estimate both univariate and multivariate regressions that include indices of trend-following and value styles of currency investing as discussed above. For the 18-month window with 151 observation periods, we find that the beta coefficient on carry is significant in roughly one quarter of the periods. When significant, the coefficient on carry ranges from about 0.25 to 0.55 , while the R-squared ranges from 0.26 to 0.71 . The size of the coefficient and high R-squared suggest that carry can be an important strategy for global macro funds, whose earnings can depend heavily on returns to the strategy. At the same time, the coefficients variability over time also suggests that as a group, a large proportion of managers may enter or exit a strategy at about the same time, enough so to affect the estimate for the Macro Total Index.

Dedicated currency funds. The second group of investors we consider are dedicated currency funds with mandates framed almost exclusively in terms of currency strategies. The dependent variable in the regressions of Table 5.1 is the return on the Barclay Currency Traders Index (BCTI), which represents the return on managed programmes that trade primarily in currency futures and forward markets. We expect carry to be a strategy pursued by a large number of funds that comprise this index. Dedicated currency traders, as a group, however are far smaller in terms of assets under management than the "global macro" fund grouping considered above. In 2014, BarclayHedge estimated that managed currency funds represented just short of $\$ 20$ billion or about $6 \%$ of assets under management in the managed futures industry. This market share is down from $11.4 \%$ in 2007 prior to the GFC. 
Estimates from Pojarliev and Levich (2008) of the style factor coefficients are shown in the first three rows of Table 5.1, using data over the period 1990-2006. The results strongly implied that the three common currency investment strategies carry, trend and value - are significant and collectively explain more than $60 \%$ of the variation in monthly returns for the BCTI over the period 1990-2006. Positive coefficients on carry and trend indicate that managers on average held positive exposure to those strategies; while the negative coefficient on value suggests that currency manager returns have generally been associated with bets against value and holding long (short) positions in overvalued (undervalued) currencies.

When the sample is divided into pre-2000 versus afterwards (2000-06), the point estimates on the coefficients suggest that managers raised their exposure to carry in the later period and lowered their exposures to trend and value. Recall that the second period is one where the underlying data indicated a very favourable carry-to-risk ratio for the AUD and NZD among others. Additional estimates of the style factor coefficients reported in Pojarliev and Levich (2012) using alternative carry and value indices confirm these results for subperiods extending through 2010.

In the fourth row of Table 5.1, we also present results for the same variables for the more recent period 2011-14, so as to coincide with periods of later regression analysis. The coefficients on carry and trend are statistically significant (carry at the $90 \%$ level), but the coefficients are lower, suggesting that exposure to carry and other style factors may not have been as important as during previous periods.

Analysis at the currency fund manager level. The analysis can also be pursued at the currency fund manager level. Pojarliev and Levich (2010) estimate equation (1) for each of 80 professional currency fund managers listed on the DB Select platform. The platform is operated by Deutsche Bank and allows customers to make investments in individual funds and observe prices and return on a daily basis with returns audited and confirmed by an independent third party. ${ }^{38}$ This data set permits the estimation of style factor coefficients for individual managers and groups of managers. In addition, because the data set includes observations on managers who delisted from the platform, the authors are able to track the performance of funds that survive until the end of the sample ("live funds") versus those that cease to report ("dead funds").

The results for three synthetic portfolios are displayed in the first three rows of Table 5.2. The first portfolio is a "fund of funds" that invests an equal amount in each manager listed on the platform at time $t$, a second fund including only managers that remain "live" at the end of the sample (26 March 2008) and a third fund that includes only managers that are "dead" by the end of the sample. The first fund of funds is investable while the other two are not, but help us inspect any differences in strategy between funds that ultimately live or die out. These results show that the three style factors are again significant and collectively explain a large proportion, some $53 \%$, of the variation in currency investment returns for the "fund of funds" that includes all managers. Notably, the portfolio of "live" managers has a slightly higher coefficient on carry, an equally large $R^{2}$, and a point estimate of excess performance (alpha) that is positive. By comparison, the portfolio of "dead"

38 This data set is unique in that regard as many hedge fund data sets are built from self-reported data that are unaudited and prone to a variety of biases. 
managers held a contrarian position on carry (as indicated by the significant negative coefficient) and did not hold a contrarian position on value in comparison to the "live" managers. These differences were costly as the "dead" managers produced significant negative alpha of 6.4 basis points per week. The decision to bet against carry too early and pursue a strategy less associated with the style factors (suggested by the smaller $R^{2}$ ) most likely contributed to the decision to delist from the platform. ${ }^{39}$

In the final row of Table 5.2, we report the most recent results of an investable fund of funds based on 32 currency fund managers returns listed on the Citi Access platform operated by Citibank (the DB data were not available for this later period). These data cover the period August 2011 through May 2014. In contrast to the BCTI regressions for the later period, all the style factors are highly significant, and together with volatility, explain a large portion (72\%) of the variation in currency investment returns for the fund of funds.

Assessing the "crowdedness" of currency investment strategies. The increasing importance of the fund management industry has led a number of economists to focus on how correlation of asset manager choices might increase fluctuations in financial markets (Feroli et al (2014)). The abundance of currency fund managers in the data set discussed above suggests a new approach to measuring herding, or "crowdedness", in currency investment strategies (Pojarliev and Levich (2011)). The key metric is based on the net proportion of currency managers who hold positions that are significantly related to an underlying style factor. Let $a_{F, t}$ be the percentage of funds with significant positive exposure to style $F$, and let $b_{F, t}$ be the percentage of funds with significant negative (or contrarian) exposure to style $F$. Then $C_{F, t}=a_{F, t}-b_{F, t}$ defines the crowdedness measure of style $F$ at time $t$.

Market participants have long instinctively appreciated that crowded trades can be both bad for returns (as prices have likely been bid up away from their economic fundamentals level) and especially risky if many investors were to attempt to unwind their positions simultaneously. Pedersen (2009) develops a formal model that demonstrates how crowding in financial markets generates a second endogenous risk from "being trampled by falling prices, margin calls, and vanishing capital" that creates another layer of risk on top of the economic risk of the position. In Pedersen's words, crowding creates "a negative externality that increases the aggregate risk".

In a study covering all funds on the DB Select platform from April 2005 to June 2010, Pojarliev and Levich (2011) find that crowdedness varied considerably over the sample period. For example, carry crowdedness varied from $-7 \%$ to $+32 \%$. Trend crowdedness varied from $-3 \%$ to $+34 \%$ and value crowdedness varied from $-28 \%$ to $+12 \%$. Prior high returns on a strategy also can lead to an increase in crowdedness while periods of low or no returns induces funds to close down or migrate to another strategy. Thus, crowding develops both by the entry of new funds and a

39 It is worth recalling that in mid-1992 George Soros famously made a contrarian carry bet by shorting the high-interest rate Italian lira and British pound and taking a long position in the Deutsche mark. Shortly thereafter authorities previously resisting the depreciation of the lira and the pound allowed their currencies to depreciate against the mark and Soros reportedly made upwards of $\$ 1$ billion on the trade. A decision to delist from the DB Select platform could be the result of numerous factors and does not imply that the manager or the fund ceased operations. 
shift by discretionary fund managers to those strategies that seem to be producing the best returns.

The relation between crowdedness and returns is highlighted for the specific case of the carry trade in Graph 5.4. As the returns on carry advanced through 2006 and into 2007, carry crowdedness, after being near zero in the early part of the sample, moved upward to $28 \%$. Crowdedness retreated along with the performance of carry into early 2008, and both turned negative after the Lehman Brothers bankruptcy in fall 2008. Although carry returns recovered in 2009 and fund managers began to crowd back into carry, carry returns fell and fund managers quickly exited the carry trade after the onset of the European sovereign crisis in 2010.

For this paper we prepared updated crowdedness estimates running through May 2014. As data from the DB Select platform were not available, for the most recent period we relied on the previously mentioned sample of 32 currency fund managers listed on the Citi Access platform operated by Citibank. These data cover the period 31 August 2011 through 28 May 2014 and provide us with 119 rolling 26 -week windows to calculate the number of managers with returns significantly related to a carry return index.

Similar to other results, we find that over this period a variable and sometimes large fraction of managers earned returns linked to carry. The proportion of funds following carry (as represented by the DB G10 Carry Index) ranged from 10\% to more than $60 \%$ as shown in Graph 5.5. Unlike the pattern observed earlier, where carry returns seemed to attract a greater crowd of investors, between Q2 2012 and Q2 2013 the carry index advanced almost 20\% but our measure of crowdedness seemed to be unaffected or possibly it declined slightly. And from Q3 2013 to the end of the sample, the carry index was essentially flat, delivering no returns, but carry crowdedness fell from over $60 \%$ to $15 \%$ in about three months. Given that the crowdedness measure depends on regression estimates over the prior 26 weeks, investment decisions made starting in April 2013 began to influence crowdedness estimates in October. The data are consistent with the possibility that the first announcements of tapering made in May and June 2013 led some currency managers to trim or exit carry trade positions, so that by early 2014 carry crowdedness had become significantly lower. Importantly, this relatively fast exit from carry was not accompanied by a decline in carry performance, suggesting that carry positions, at least during this period, could be liquidated without a large market price impact.

\section{Summary and conclusions}

In this paper, we have explored the development and functioning of the foreign exchange markets in Asia and the Pacific from a variety of perspectives.

From the perspective of sheer size, at $\$ 5.3$ trillion per day global FX turnover represents a staggering figure. Global turnover in FX has expanded more than fourfold in the dozen years between 2001 and the latest 2013 BIS Triennial Survey. Turnover for Asia-Pacific currencies has kept pace and in many cases shown a higher rate of growth since 2010 than for currencies from other regions. Offshore trading is another prominent and growing trend, and once again Asia-Pacific 
currencies have demonstrated higher offshore growth vis-à-vis both advanced economy and emerging market currencies. While many Asia-Pacific currencies stand out in these trends, the Chinese renminbi is noteworthy for exceptionally high rates of turnover growth. The RMB is now the second most actively traded EM currency (behind the Mexican peso) and the ninth most actively traded currency in the world.

In a parallel trend, non-deliverable forward contracts have become more important both as a vehicle for hedging and speculative purposes, but also as a means of price discovery when the alternative delivered forward contract is constrained. And finally, the rising importance of non-dealer financial institutions points to a growing cadre of counterparties that may pose growing risks for traditional FX market-makers.

With such enormous daily turnover and diverse counterparties, robust operating and risk management systems are essential to safeguard the narrow FX market and the broader financial system. Surprisingly, although FX is a critical element of the global economy, the market is not subject to significant regulatory oversight. Moreover, while the Dodd-Frank Act imposes CCP margin requirements and marking to market on most derivative positions, outright $\mathrm{FX}$ forwards and swaps, which together accounted for $55 \%$ of global FX turnover in 2013, are exempt from the CCP mandate. This decision hinges on several factors - FX forwards tend to be very short-maturity contracts, while FX swaps require both parties to physically exchange the full amount of currency at fixed terms known at the outset of the contract, and the CLS Bank virtually eliminates settlement risk from FX trading.

The CLS Bank is the most critical FX market innovation over the last 20 years and it has had a profound impact on safeguarding the market and mitigating the risks of trading. While, by some measures, the reach of the CLS Bank may appear limited - only 17 CLS-enabled currencies and fewer than 100 settlement members the 17 CLS-enabled currencies account for more than $90 \%$ of all global FX turnover, and access to CLS extends to more than 10,000 third-party members. Our analysis reveals that Asia-Pacific countries and currencies are well represented in the CLS system, and along with several alternative PVP systems, the region has access to PVP settlement on a par with countries in the rest of the world.

In practice, there are no precise estimates of what fraction of global FX turnover benefits from risk mitigation by using the CLS Bank or alternative PVP settlement systems available in several other Asia-Pacific countries. Preliminary results from a survey by CLS of its members suggest that roughly $55 \%$ of global turnover may be settled through CLS. However, much of the remaining turnover may be settled "on us" within a single bank (and not subject to settlement risk) or benefit through bilateral netting, which reduces the amounts at risk relative to the gross turnover figures. Our estimates suggest that possibly $\$ 450$ billion of daily turnover in CLS currencies and another $\$ 167$ billion in daily turnover for non-CLS currencies may be subject to gross non-PVP settlement risks. Clearly, the $\$ 617$ billion of daily FX turnover settled through non-PVP systems represents a substantial risk, and underscores why countries generally and the Asia-Pacific region in particular would benefit by having more currencies become CLS-enabled or tradable under other PVP systems.

The "taper tantrum" announcements in 2013 offer an opportunity to examine how Asia-Pacific currencies have reacted to news that, owing to the continuing central importance of the US economy and US monetary policy, could impact financial markets and economies elsewhere. Our analysis focused on the impact of 
tapering announcements on FX rates, on market liquidity (as proxied by bid-ask spreads), on volatility, on deviations from covered interest parity, and on the gap between onshore forward rates and their offshore, NDF counterpart rates. In the case of both exchange rates and implied volatilities, we find that Asia-Pacific currencies responded quickly to tapering announcements, but with some surprising variation. The currencies of countries with larger turnover and better fundamentals tended to react more immediately, while implied volatilities tended to rise more for the other currencies. Over the entire period, depreciation was also more evident for the latter group of currencies. In contrast to the global finance crisis, deviations from covered interest parity were minimal; neither did bid-ask spreads noticeably move. For two of the five currencies for which NDF market data were available, price discovery appears to take place first in the overseas market, leading to significant onshore-NDF premia.

Finally, we examined currency carry trades as a well known investment strategy that at times has seemed to present a disruptive element in cross-border currency flows and an additional source of instability at times of financial stress. The carry trade has been an attractive investment strategy over the last 20-30 years, both in its own right (in terms of a high return compared with its own risk) and also as a strategy to pair with other investment strategies in currency or other asset classes. Most previous studies have found it difficult to estimate how intensely carry strategies are used. An exception is prior research by Pojarliev and Levich (2011), who trace the number of professional currency managers whose returns significantly track the returns on carry and other currency investment strategies. In this paper, we extend that analysis and find that, indeed, many currency managers as well as global macro hedge fund managers have taken positions so that their funds produce returns that track a currency carry index. While, in earlier periods, currency managers seemed prone to herding into carry when it was performing well and then unwinding their positions in near unison when returns turned negative, the recent experience does not show evidence of herding in response to positive carry returns. And there is some evidence to suggest that the tapering announcements led to a comparatively orderly withdrawal from carry, without causing any apparent market disruptions.

The common thread across all of these various perspectives is that the development and functioning of FX markets in the Asia-Pacific region seems to be proceeding at a slightly faster pace than other regions, but that operational safeguards such as access to CLS and PVP settlement as well as other risk-mitigating measures are on a par with those of other regions or perhaps slightly ahead of them. Although we document interesting cross-country differences in the market response to several recent US monetary policy-related announcements of exchange rates and related volatilities, on the whole there were few signs of the illiquidity in markets of the sort that characterised the global financial crisis. Similarly, professional investors have moved into and out of carry, but there is no evidence over the last several years of herding or rapid unwinds that have been observed in previous cycles.

While these developments lend confidence, vulnerability remains present because currencies within the region are a popular vehicle for global carry trades and other investment strategies, and all currencies respond when the jurisdiction of the key global currency (ie the US dollar) considers a change in monetary policy. It is worth keeping in mind that the post-GFC period has witnessed a general decline in currency volatility as well as a general reduction in interest rates worldwide. Should 
monetary policies and economic performance begin to diverge more than in the recent past, currency volatility and expected rate movements may return. Continuing to promote risk-mitigating systems such as CLS Bank and alternative PVP arrangements and tracking the crowdedness of certain currency strategies such as the carry trade that are prone to unusual risks would seem to be advisable policy recommendations; they should promote the integrity and resilience of the global FX market and the related markets that depend on it. 


\begin{tabular}{|c|c|c|c|c|c|c|}
\hline & \multicolumn{5}{|c|}{ Net-net basis, ${ }^{1}$ percentage share of average daily turnover in April ${ }^{2}$} & \multirow{2}{*}{$\begin{array}{l}\text { Growth } \\
2010-13\end{array}$} \\
\hline & 2001 & 2004 & 2007 & 2010 & 2013 & \\
\hline US dollar & 89.9 & 88.0 & 85.6 & 84.9 & 87.0 & 38.0 \\
\hline Euro & 37.9 & 37.4 & 37.0 & 39.1 & 33.4 & 15.1 \\
\hline Japanese yen & 23.5 & 20.8 & 17.2 & 19.0 & 23.0 & 63.3 \\
\hline Australian dollar & 4.3 & 6.0 & 6.6 & 7.6 & 8.6 & 53.2 \\
\hline Swiss franc & 6.0 & 6.0 & 6.8 & 6.3 & 5.2 & 10.0 \\
\hline Canadian dollar & 4.5 & 4.2 & 4.3 & 5.3 & 4.6 & 16.3 \\
\hline New Zealand dollar & 0.6 & 1.1 & 1.9 & 1.6 & 2.0 & 65.6 \\
\hline Other developed markets & 18.2 & 20.9 & 20.5 & 17.0 & 15.8 & 25.3 \\
\hline Emerging markets & 8.6 & 9.0 & 12.5 & 14.8 & 18.8 & 71.4 \\
\hline Others & 6.5 & 6.5 & 7.5 & 4.6 & 1.6 & $\ldots$ \\
\hline Total & 200.0 & 200.0 & 200.0 & 200.0 & 200.0 & 34.6 \\
\hline
\end{tabular}

${ }^{1}$ Adjusted for local and cross-border inter-dealer double-counting (ie "net-net" basis). ${ }^{2}$ Because two currencies are involved in each transaction, the sum of the percentage shares of individual currencies totals $200 \%$ instead of $100 \%$.

Source: BIS Triennial Central Bank Survey.

Currency distribution of global foreign exchange market turnover, emerging markets

Table 2.2

\begin{tabular}{|c|c|c|c|c|c|c|}
\hline & \multicolumn{5}{|c|}{ Net-net basis, ${ }^{1}$ percentage share of average daily turnover in April $^{2}$} & \multirow{2}{*}{$\begin{array}{c}\text { Growth } \\
2013\end{array}$} \\
\hline & 2001 & 2004 & 2007 & 2010 & 2013 & \\
\hline Mexican peso & 0.8 & 1.1 & 1.3 & 1.3 & 2.5 & 170.9 \\
\hline Chinese renminbi & 0.0 & 0.1 & 0.5 & 0.9 & 2.2 & 249.0 \\
\hline Russian rouble & 0.3 & 0.6 & 0.7 & 0.9 & 1.6 & 138.2 \\
\hline Hong Kong dollar & 2.2 & 1.8 & 2.7 & 2.4 & 1.4 & -17.6 \\
\hline Singapore dollar & 1.1 & 0.9 & 1.2 & 1.4 & 1.4 & 32.5 \\
\hline Turkish lira & 0.0 & 0.1 & 0.2 & 0.7 & 1.3 & 140.1 \\
\hline Korean won & 0.8 & 1.1 & 1.2 & 1.5 & 1.2 & 6.5 \\
\hline South African rand & 0.9 & 0.7 & 0.9 & 0.7 & 1.1 & 107.8 \\
\hline Brazilian real & 0.5 & 0.3 & 0.4 & 0.7 & 1.1 & 117.4 \\
\hline Indian rupee & 0.2 & 0.3 & 0.7 & 1.0 & 1.0 & 39.8 \\
\hline Indonesian rupiah & 0.0 & 0.1 & 0.1 & 0.2 & 0.2 & 50.2 \\
\hline Malaysian ringgit & 0.1 & 0.1 & 0.1 & 0.3 & 0.4 & 94.6 \\
\hline Thai baht & 0.2 & 0.2 & 0.2 & 0.2 & 0.3 & 123.4 \\
\hline Philippine peso & 0.0 & 0.0 & 0.1 & 0.2 & 0.1 & 16.2 \\
\hline Other emerging markets & 1.4 & 1.6 & 2.2 & 2.6 & 2.9 & 49.6 \\
\hline Others & 6.5 & 6.5 & 7.5 & 4.6 & 1.6 & $\ldots$ \\
\hline Total & 200.0 & 200.0 & 200.0 & 200.0 & 200.0 & 34.6 \\
\hline
\end{tabular}


Offshore trading of emerging market currencies, 2013

Daily average in April, ${ }^{1}$ share in total - onshore and offshore - OTC FX market turnover

Table 2.3

\begin{tabular}{|c|c|c|c|c|c|c|c|c|c|}
\hline & $\begin{array}{l}\text { Offshore } \\
\text { turnover }\end{array}$ & $\begin{array}{l}\text { Offshore } \\
\text { share in } \\
\text { global } \\
\text { turnover }\end{array}$ & $\begin{array}{l}\text { Intra- } \\
\text { regional } \\
\text { share }^{2}\end{array}$ & $\begin{array}{l}\text { Share of } \\
\text { regional } \\
\text { financial } \\
\text { centres }^{3}\end{array}$ & UK & US & $\begin{array}{l}\text { Euro } \\
\text { zone }\end{array}$ & Other & $\begin{array}{c}\% \\
\text { change } \\
\text { since } \\
2007^{4}\end{array}$ \\
\hline & USD bn & \multicolumn{8}{|c|}{ In per cent } \\
\hline Advanced economies & $7,607.0$ & 79.2 & $\ldots$ & $\ldots$ & 45.3 & 20.6 & 5.7 & $\ldots$ & 8.54 \\
\hline Japanese yen & $1,024.1$ & 83.2 & $\ldots$ & $\ldots$ & 44.7 & 21.1 & 3.8 & $\ldots$ & 14.9 \\
\hline Australian dollar & 395.5 & 85.7 & $\ldots$ & $\ldots$ & 42.1 & 19.6 & 5.0 & $\ldots$ & 18.1 \\
\hline New Zealand dollar & 97.8 & 93.4 & $\ldots$ & $\ldots$ & 36.9 & 24.0 & 3.2 & $\ldots$ & 9.4 \\
\hline Emerging market currencies & 678.7 & 67.4 & 12.6 & $\ldots$ & 29.9 & 16.4 & 4.6 & 3.9 & 22.9 \\
\hline Emerging Asian currencies & 277.2 & 59.2 & 26.6 & 25.3 & 18.8 & 5.8 & 2.6 & 2.8 & 19.4 \\
\hline Chinese renminbi & 86.1 & 72.0 & 45.5 & 43.7 & 18.0 & 8.9 & 1.6 & 1.2 & 56.1 \\
\hline Hong Kong dollar & 40.7 & 52.6 & 10.7 & 8.1 & 22.9 & 15.5 & 5.1 & 5.0 & 1.0 \\
\hline Singapore dollar & 48.8 & 65.4 & 12.6 & 11.4 & 27.8 & 7.1 & 3.7 & 5.8 & 15.6 \\
\hline Korean won & 27.4 & 42.7 & 21.2 & 21.1 & 11.3 & 8.5 & 1.5 & 1.6 & 14.2 \\
\hline Indian rupee & 28.0 & 53.0 & 27.0 & 26.9 & 15.1 & 7.0 & 1.1 & 1.5 & 30.3 \\
\hline Indonesia rupiah & 6.2 & 68.5 & 40.2 & 31.5 & 17.4 & 4.7 & 2.0 & 1.9 & 23.2 \\
\hline Malaysian ringgit & 13.8 & 64.6 & 36.4 & 36.3 & 19.8 & 4.9 & 1.6 & 2.0 & 39.6 \\
\hline Thai baht & 7.7 & 44.8 & 19.7 & 19.2 & 13.4 & 6.6 & 3.6 & 3.2 & 25.9 \\
\hline Philippine peso & 5.1 & 65.5 & 35.3 & 35.0 & 18.2 & 8.5 & 3.8 & 1.7 & 23.7 \\
\hline \multicolumn{10}{|c|}{$\begin{array}{l}{ }^{1} \text { Adjusted for local and cross-border inter-dealer double-counting (ie "net-net" basis). }{ }^{2} \text { Intraregional is defined as all offshore trades } \\
\text { within the respective emerging market region. }{ }^{3} \text { Hong Kong SAR and Singapore. }{ }^{4} \text { Annualised change. }\end{array}$} \\
\hline
\end{tabular}


OTC FX market turnover in the Pacific regions - by counterparty

Daily average in April, ${ }^{1}$ in billions of US dollars

Table 2.4

\begin{tabular}{lrrr|rrr}
\hline & \multicolumn{3}{c}{ Spot } & \multicolumn{3}{c}{$\begin{array}{c}\text { FX } \\
\text { derivatives }\end{array}$} \\
\cline { 2 - 7 } & $\begin{array}{l}\text { Reporting } \\
\text { dealers }\end{array}$ & Other FIs & Non-FIs & \multicolumn{1}{c}{$\begin{array}{c}\text { Reporting } \\
\text { dealers }\end{array}$} & Other FIs & Non-FIs \\
\cline { 2 - 7 } Emerging market & 119.300 & 64.807 & 52.691 & 302.829 & 169.846 & 62.813 \\
Emerging Asia & 90.476 & 40.344 & 33.792 & 249.668 & 115.294 & 44.319 \\
$\quad$ China & 5.498 & 7.747 & 8.739 & 8.932 & 6.790 & 3.030 \\
Hong Kong SAR & 19.217 & 9.335 & 6.483 & 92.211 & 50.458 & 10.815 \\
India & 6.652 & 4.198 & 2.563 & 8.945 & 2.562 & 3.289 \\
Indonesia & 0.783 & 0.525 & 1.594 & 0.745 & 0.427 & 0.213 \\
Korea & 11.645 & 3.510 & 2.692 & 17.703 & 3.533 & 2.099 \\
Malaysia & 1.866 & 1.601 & 0.463 & 1.955 & 1.428 & 1.726 \\
Philippines & 0.949 & 0.133 & 0.213 & 1.480 & 0.294 & 0.154 \\
Singapore & 42.074 & 12.612 & 9.514 & 113.756 & 48.655 & 21.280 \\
Thailand & 1.793 & 0.681 & 1.529 & 3.941 & 1.146 & 1.712 \\
Developed market & 556.059 & $1,117.883$ & 135.417 & 1091.781 & 1456.900 & 214.221 \\
Australia & 18.831 & 12.114 & 2.914 & 54.912 & 31.067 & 8.151 \\
Japan & 54.433 & 18.439 & 40.314 & 87.103 & 38.925 & 22.850 \\
New Zealand & 0.369 & 0.607 & 0.862 & 3.425 & 2.446 & 0.901 \\
\hline
\end{tabular}

${ }^{1}$ Adjusted for local and cross-border inter-dealer double-counting (ie "net-net" basis).

Sources: BIS Triennial Central Bank Survey; authors calculations. 
CLS-enabled currencies as of September 2014 and turnover as of April 2013

Table 3.1

\begin{tabular}{lccc}
\hline & Currency & Turnover(\%) & Rank in BIS Triennial Central Bank \\
Survey 2013
\end{tabular}

${ }^{1}$ Percentage shares of average daily turnover in April 2013.

Source: BIS Triennial Central Bank Survey. 
The CLS community in the Asia-Pacific and other countries

\begin{tabular}{|c|c|c|c|}
\hline & Asia-Pacific & Other countries & Total \\
\hline \multirow[t]{2}{*}{ Countries/currencies } & 6 & 11 & 17 \\
\hline & $(35.2 \%)$ & $(64.8 \%)$ & $(100.0 \%)$ \\
\hline \multirow[t]{2}{*}{ Countries with shareholders } & 5 & 18 & 23 \\
\hline & $(21.7 \%)$ & $(78.3 \%)$ & $(100.0 \%)$ \\
\hline \multirow[t]{2}{*}{ Shareholders, by country } & 15 & 61 & 76 \\
\hline & $(19.7 \%)$ & $(80.3 \%)$ & $(100.0 \%)$ \\
\hline \multirow[t]{2}{*}{ Settlement members ${ }^{1}$} & 18 & 46 & 64 \\
\hline & $(28.1 \%)$ & (71.9\%) & $(100.0 \%)$ \\
\hline \multirow{2}{*}{$\begin{array}{l}\text { Third-party members, } \\
\text { by BIC name }\end{array}$} & 774 & 10,865 & 11,639 \\
\hline & $(6.7 \%)$ & (93.3\%) & $(100.0 \%)$ \\
\hline \multicolumn{4}{|l|}{ Memo: } \\
\hline \multicolumn{4}{|c|}{ BIS Triennial Central Bank Survey 2013} \\
\hline \multirow[t]{2}{*}{ Number of countries } & 13 & 40 & 53 \\
\hline & $(24.5 \%)$ & $(75.5 \%)$ & $(100.0 \%)$ \\
\hline \multirow{2}{*}{$\begin{array}{l}\text { FX turnover by country } \\
\text { (in trillions of US dollars) }\end{array}$} & $\$ 1,407$ & $\$ 5,264$ & $\$ 6,671$ \\
\hline & $(21.1 \%)$ & (78.9\%) & $(100.0 \%)$ \\
\hline \multirow{2}{*}{$\begin{array}{l}\text { FX turnover by currency } \\
\text { (in trillions of US dollars) }\end{array}$} & $\$ 1,133$ & $\$ 4,212$ & $\$ 5,345$ \\
\hline & (21.2\%) & (78.8\%) & (100.0\%) \\
\hline
\end{tabular}

Note: CLS data are as of June 2014.

${ }^{1}$ Include two user members, one from the Asia-Pacific and one from elsewhere. ${ }^{2}$ For 54 countries; net-gross basis. ${ }^{3}$ For 53 countries; net-net basis.

Sources: Private correspondence with CLS; CLS bank website; BIS Triennial Central Bank Survey.

Share of FX turnover eligible for CLS and other PVP settlement

All global FX trading ${ }^{1}$

\begin{tabular}{rcc} 
CLS bank & Other PVP arrangements & Total \\
\hline $90.46 \%$ & $1.15 \%$ & $91.61 \%$ \\
$92.93 \%$ & $\ldots$ & $\ldots$ \\
$90.93 \%$ & $\ldots$ & $\ldots$ \\
$89.79 \%$ & $2.78 \%$ & $92.56 \%$ \\
$90.43 \%$ & $1.16 \%$ & $91.59 \%$
\end{tabular}

Among Asia-Pacific pairs only

Among non-Asia-Pacific pairs

$1.16 \%$

$91.59 \%$

Non-Asia-Pacific vs any currency

${ }^{1}$ Based on 40 individual currencies in the 2013 BIS Triennial Central Bank Survey and data on trading in 273 unique currency pairs. Eligible trading for CLS covers 17 currencies and 136 unique currency pairs including six Asia-Pacific currencies and 11 non-Asia-Pacific. See notes to Graph 3.2 for additional details.

Sources: BIS Triennial Central Bank Survey; authors' calculations. 
Turnover among CLS-enabled currency pairs and non-CLS pairs as of April $2013^{1}$

Table 3.4

\begin{tabular}{|c|c|c|c|c|}
\hline \multirow[t]{2}{*}{ Turnover among } & & \multicolumn{2}{|c|}{ Turnover } & \multirow[t]{2}{*}{ Percent of total } \\
\hline & & Millions per day & $\begin{array}{c}\text { Region in Graph } \\
3.2\end{array}$ & \\
\hline \multirow[t]{4}{*}{ Two CLS currencies } & Both Asia-Pacific & 52,903 & $x 8$ & $1.05 \%$ \\
\hline & $\begin{array}{l}\text { One Asia-Pacific and } \\
\text { one non-Asia-Pacific }\end{array}$ & $1,826,111$ & X3 & $36.10 \%$ \\
\hline & Both non-Asia-Pacific & $2,696,529$ & $\mathrm{X} 1$ & $53.31 \%$ \\
\hline & Sub-total & & $4,575,543$ & $90.46 \%$ \\
\hline \multirow{5}{*}{$\begin{array}{l}\text { One CLS and one non-CLS } \\
\text { currency }\end{array}$} & Both Asia-Pacific & 4,027 & $x 9$ & $0.08 \%$ \\
\hline & $\begin{array}{l}\text { One Asia-Pacific and } \\
\text { one non-Asia-Pacific }\end{array}$ & 209,738 & $x 4+x 6$ & $4.15 \%$ \\
\hline & Both non-Asia-Pacific & 269,023 & $\mathrm{x} 2$ & $5.32 \%$ \\
\hline & Sub-total & & 482,789 & $9.54 \%$ \\
\hline & Total & $5,058,331$ & $5,058,331$ & $100.00 \%$ \\
\hline
\end{tabular}

The CLS currencies in Asia-Pacific region are AUD, HKD, JPY, KRW, NZD and SGD. The CLS currencies in non-Asia-Pacific region are CAD, CHF, DKK, EUR, GBP, ILS, MXN, NOK, SEK, USD and ZAR. The non-CLS currencies in Asia-Pacific region are CNY, INR, TWD, MYR, THB, IDR and PHP. The non-CLS currencies in non-Asia-Pacific region are ARS, BGN, BHD, BRL, CLP, COP, CZK, HUF, LTL, LVL, PEN, PLN, RON, RUB, TRY and SAR.

${ }^{1}$ No turnover data are available with both legs of a transaction involving a non-CLS currency (regions X5, X7 and X10). See notes to Graph 3.2 for additional details. The figures in this table exclude $\$ 285$ billion of global turnover that are classified as other or residual and cannot be assigned to a specific currency pair in Graph 3.2.

Sources: BIS Triennial Central Bank Survey; authors' calculations. 
Changes to bilateral exchange rate ${ }^{1}$ in percentage points

Table 4.1

\begin{tabular}{lcccccccccccc}
\hline & CNY & INR & IDR & KRW & MYR & PHP & SGD & THB & AUD & JPY & NZD & HKD \\
\cline { 2 - 11 } 22 May 2013 & -0.07 & -0.14 & -0.06 & $\mathbf{- 1 . 3 0}$ & -0.43 & $\mathbf{- 1 . 2 0}$ & -0.02 & -0.43 & 0.27 & $\mathbf{2 . 0 4}$ & 0.38 & -0.02 \\
19 Jun 2013 & -0.15 & $\mathbf{- 1 . 6 9}$ & -0.18 & $\mathbf{- 1 . 3 0}$ & $\mathbf{- 1 . 4 7}$ & $\mathbf{- 1 . 3 2}$ & $\mathbf{- 1 . 6 8}$ & $\mathbf{- 1 . 4 6}$ & $\mathbf{- 3 . 7 0}$ & $\mathbf{- 3 . 1 4}$ & $\mathbf{- 3 . 9 7}$ & 0.01 \\
18 Dec 2013 & -0.02 & -0.21 & -0.35 & $\mathbf{- 0 . 8 3}$ & -0.55 & -0.39 & $\mathbf{- 0 . 6 1}$ & -0.51 & -0.34 & -0.98 & -0.78 & -0.01 \\
SUM $^{2}$ & -0.24 & $\mathbf{- 1 . 9 4}$ & -0.59 & $\mathbf{- 3 . 4 3}$ & $\mathbf{- 2 . 4 5}$ & $\mathbf{- 2 . 9 1}$ & $\mathbf{- 2 . 3 1}$ & $\mathbf{- 2 . 4 0}$ & $\mathbf{- 3 . 2 7}$ & $\mathbf{- 1 . 1 1}$ & $\mathbf{- 4 . 3 0}$ & -0.03 \\
22 May - 18 Dec $^{3}$ & 0.83 & -10.58 & -20.0 & 5.07 & -7.71 & -7.35 & -0.21 & -8.21 & -8.52 & -0.70 & 1.10 & 0.10 \\
\hline
\end{tabular}

${ }^{1}$ Against the US dollar, a positive number indicates an appreciation of the local currency; one-day change. Numbers in bold significantly different from zero at $95 \%$ confidence level. 2 The sum of one-day changes after three "taper" announcement days, 22 May, 19 Jun, 18 Dec 2013. ${ }^{3}$ Change between 22 May and 19 December 2013.

Sources: Datastream; authors' calculations.

Changes to relative bid-ask spreads, ${ }^{1}$ in basis points

Table 4.2

\begin{tabular}{lrrrrrrrrrrrr}
\hline & CNY & INR & IDR & KRW & MYR & PHP & SGD & THB & AUD & JPY & NZD & HKD \\
\cline { 2 - 11 } 22 May 2013 & 0.00 & 0.45 & 0.00 & -0.04 & -0.04 & -0.03 & 0.79 & $\mathbf{1 3 . 3}$ & 0.01 & 0.06 & -0.06 & 0.13 \\
19 Jun 2013 & -2.29 & -0.03 & 5.03 & 0.84 & -0.45 & -0.06 & -0.09 & -3.45 & 0.27 & -0.10 & -1.02 & 0.13 \\
18 Dec 2013 & 0.33 & 0.00 & -4.18 & 0.92 & -3.11 & -1.14 & -0.03 & 3.02 & -0.01 & 0.93 & 0.03 & 0.00 \\
SUM $^{2}$ & -1.97 & 0.42 & 0.84 & 1.72 & -3.60 & -1.23 & 0.66 & 12.90 & 0.27 & 0.89 & -1.04 & 0.26 \\
\hline
\end{tabular}

${ }^{1}$ Relative bid-ask spreads are expressed in basis points against the mid-quote; indicative quotes against the US dollar; one-day change. Numbers in bold significantly different from zero at $95 \%$ confidence level. ${ }^{2}$ The sum of one-day changes after three "taper" announcement days, 22 May, 19 Jun, 18 Dec 2013.

Sources: Datastream; authors' calculations.

Changes to one-month implied volatility, ${ }^{1}$ in percentage points

Table 4.3

\begin{tabular}{lrrrrrrrrrrrr}
\hline & CNY & \multicolumn{1}{c}{ INR } & IDR & KRW & MYR & PHP & SGD & THB & AUD & JPY & NZD & HKD \\
\cline { 2 - 11 } 22 May 2013 & 0.13 & 0.54 & 0.38 & $\mathbf{0 . 8 8}$ & $\mathbf{0 . 7 4}$ & $\mathbf{1 . 9 5}$ & $\mathbf{0 . 7 1}$ & -0.02 & 0.15 & $\mathbf{1 . 0 0}$ & 0.30 & 0.00 \\
19 Jun 2013 & 0.10 & $\mathbf{1 . 0 9}$ & $\mathbf{3 . 0 0}$ & $\mathbf{1 . 6 3}$ & $\mathbf{1 . 5 6}$ & $\mathbf{1 . 2 6}$ & $\mathbf{1 . 3 8}$ & -0.12 & $\mathbf{1 . 6 0}$ & 0.30 & $\mathbf{1 . 5 5}$ & 0.00 \\
18 Dec 2013 & -0.03 & -0.74 & -0.25 & -0.06 & -0.47 & -0.26 & 0.01 & -0.30 & $\mathbf{- 0 . 8 5}$ & -0.80 & $-\mathbf{0 . 9 5}$ & 0.00 \\
SUM $^{2}$ & 0.20 & 0.89 & $\mathbf{3 . 1 3}$ & $\mathbf{2 . 4 5}$ & $\mathbf{1 . 8 2}$ & $\mathbf{2 . 9 4}$ & $\mathbf{2 . 1 1}$ & -0.44 & 0.90 & 0.50 & 0.90 & 0.00 \\
\hline
\end{tabular}

${ }^{1}$ At the money against the US dollar, in percentage point, a positive number indicates an increase of volatility; one-day change. Numbers in bold significantly different from zero at $95 \%$ confidence level. ${ }^{2}$ The sum of one-day changes after three "taper" announcement days, 22 May, 19 Jun, 18 Dec 2013.

Sources: JPMorgan Chase; authors' calculations. 
Change of deviation from covered interest parity ${ }^{1}$, in delta unit

Table 4.4

\begin{tabular}{lcccccccccccc}
\hline & CNY & INR & IDR & KRW & MYR & PHP & SGD & THB & AUD & JPY & NZD & HKD \\
\cline { 2 - 11 } 22 May 2013 & 0.05 & 0.14 & 0.11 & 0.11 & 0.02 & -0.01 & -0.01 & 0.03 & 0.05 & 0.01 & -0.01 & 0.00 \\
19 Jun 2013 & 0.22 & -0.01 & 0.03 & $\mathbf{0 . 1 6}$ & 0.28 & -0.05 & $\mathbf{- 0 . 0 3}$ & $\mathbf{0 . 0 9}$ & -0.02 & 0.00 & 0.10 & $\mathbf{- 0 . 0 8}$ \\
18 Dec 2013 & 0.12 & 0.07 & -0.05 & -0.02 & 0.05 & $\mathbf{0 . 6 0}$ & -0.01 & -0.04 & 0.07 & 0.01 & 0.09 & 0.00 \\
SUM $^{2}$ & 0.39 & 0.21 & 0.09 & $\mathbf{0 . 2 5}$ & 0.35 & 0.55 & $\mathbf{- 0 . 0 5}$ & 0.08 & 0.10 & 0.02 & 0.18 & $\mathbf{- 0 . 0 7}$ \\
\hline
\end{tabular}

${ }^{1}$ Computed as the difference between the three-month FX swap-implied US dollar interest rate and three-month US dollar Libor, in per cent; the former is derived from the covered interest parity condition based on the domestic three-month interest rates; one-day change. Numbers in bold significantly different from zero at $95 \%$ confidence level. ${ }^{2}$ The sum of one-day changes after three "taper" announcement days, 22 May, 19 Jun, 18 Dec 2013.

Sources: Bloomberg, Datastream, authors' calculations.

Changes to onshore less offshore foreign exchange forward premia ${ }^{1}$

Table 4.5

\begin{tabular}{lcccccc}
\hline & CNY & INR & IDR & KRW & MYR & PHP \\
\cline { 2 - 7 } 22 May 2013 & -0.05 & -0.07 & -0.07 & 0.43 & -0.09 & 0.21 \\
19 June 2013 & -0.11 & 0.22 & $\mathbf{- 2 . 2 5}$ & $\mathbf{- 1 . 4 0}$ & -0.13 & $\mathbf{- 1 . 9 6}$ \\
18 December 2013 & -0.03 & -0.13 & -0.15 & 0.22 & -0.07 & -0.15 \\
\hline SUM $^{2}$ & -0.19 & -0.02 & $\mathbf{- 2 . 4 7}$ & -0.74 & -0.29 & $\mathbf{- 1 . 9 0}$ \\
\hline
\end{tabular}

1 The forward premium gaps are calculated as the difference between onshore forward and offshore NDF as a percentage of the spot price; two-day change. Numbers in bold significantly different from zero at $95 \%$ confidence level. ${ }^{2}$ The sum of one-day changes after three "taper" announcement days, 22 May, 19 Jun, 18 Dec 2013.

Sources: Bloomberg; authors' calculations. 


\begin{tabular}{|c|c|c|c|c|c|c|}
\hline \multirow{2}{*}{$\begin{array}{l}\text { Dependent variable: } \\
\text { excess currency return }{ }^{1}\end{array}$} & \multirow[t]{2}{*}{ Alpha } & \multicolumn{4}{|c|}{ Beta $^{2}$} & \multirow[t]{2}{*}{$\mathrm{R}^{2}$} \\
\hline & & Carry & Trend & Value & Volatility & \\
\hline \multirow[t]{2}{*}{ Jan 1990-Dec 2006} & -9 bps & 0.70 & 1.28 & -1.01 & 0.04 & 0.68 \\
\hline & $(-0.72)$ & $(3.30)$ & (17.44) & $(-2.25)$ & $(0.43)$ & \\
\hline \multirow[t]{2}{*}{ Jan 1990-Dec 2000} & $-16 \mathrm{bps}$ & 0.74 & 1.44 & -1.38 & -0.04 & 0.68 \\
\hline & $(-0.72)$ & $(2.78)$ & $(14.91)$ & $(-2.44)$ & $(-0.38)$ & \\
\hline \multirow[t]{2}{*}{ Jan 2001-Dec 2006} & -11 bps & 1.03 & 0.77 & -0.64 & 0.33 & 0.77 \\
\hline & $(-1.00)$ & $(3.99)$ & $(9.71)$ & $(-1.01)$ & (3.09) & \\
\hline \multirow[t]{2}{*}{ Jan 2011-Jul 2014} & $0.1 \mathrm{bps}$ & 0.11 & 0.15 & 0.03 & 0.003 & 0.42 \\
\hline & $(0.87)$ & $(1.69)$ & $(3.05)$ & $(0.44)$ & (2.99) & \\
\hline \multicolumn{7}{|c|}{ T-values in parentheses. Numbers in bold significantly different from zero at $95 \%$ confidence level. } \\
\hline \multicolumn{7}{|c|}{$\begin{array}{l}{ }^{1} \text { Barclays Currency Traders Index. }{ }^{2} \text { Regressors for carry, trend, value and volatility are Citibank Beta1 G10 Carry Index, AFX Index, } \\
\text { Citibank Beta1 G10 PPP Index and implied volatility respectively. For sample period Jan 2011-Jul 2014, regressors for carry and value are } \\
\text { Deutsche Bank G10 Harvest Index and Deutsche Bank FX PPP Index respectively. }\end{array}$} \\
\hline
\end{tabular}

Excess currency returns for individual managers as a function of four factors

Table 5.2

\begin{tabular}{|c|c|c|c|c|c|c|}
\hline \multirow{3}{*}{$\begin{array}{l}\text { Investable FoF } \\
\text { DB platform }{ }^{1}(2005-2008)\end{array}$} & \multirow[t]{2}{*}{ Alpha } & \multicolumn{4}{|c|}{ Beta } & \multirow[t]{2}{*}{$R^{2}$} \\
\hline & & Carry & Trend & Value & Volatility & \\
\hline & $0.1 \mathrm{bps}$ & 0.14 & 0.40 & -0.08 & 0.12 & \multirow[t]{2}{*}{0.534} \\
\hline & $(0.31)$ & (6.03) & (10.88) & $(-3.85)$ & $(1.53)$ & \\
\hline \multirow[t]{2}{*}{ "Live" FoF } & $2.7 \mathrm{bps}$ & 0.19 & 0.45 & -0.10 & 0.15 & \multirow[t]{2}{*}{0.550} \\
\hline & (1.16) & (7.21) & (10.70) & $(-4.25)$ & (1.74) & \\
\hline \multirow[t]{2}{*}{ "Dead" FoF } & -6.4 bps & -0.06 & 0.23 & 0.02 & -0.01 & \multirow[t]{2}{*}{0.183} \\
\hline & $(-2.31)$ & $(-2.12)$ & (4.57) & $(0.75)$ & $(-0.15)$ & \\
\hline \multirow{3}{*}{$\begin{array}{l}\text { Investable FoF } \\
\text { Citi platform }{ }^{2}(2011-2014)\end{array}$} & 01 hnc & 72 0 & 022 & 024 & $0 \cap 09$ & \multirow{3}{*}{0.719} \\
\hline & $0.1 \mathrm{dps}$ & 0.21 & 0.35 & 0.34 & 0.000 & \\
\hline & $(0.96)$ & (3.09) & (4.44) & (2.67) & (3.24) & \\
\hline
\end{tabular}

T-values in parentheses. Numbers in bold significantly different from zero at $95 \%$ confidence level.

${ }^{1}$ All funds on the DB Select platform, and those that are live or dead as of 3/26/2008. Based on 156 weekly returns, 6 April 2005 to 26 March 2008. ${ }^{2}$ All funds on the Citi Access platform, monthly data.

Sources: Pojarliev and Levich (2010); authors' calculations. 
CLS bank, volume of transactions and value of trades

Three-month moving average of daily data

Graph 3.1

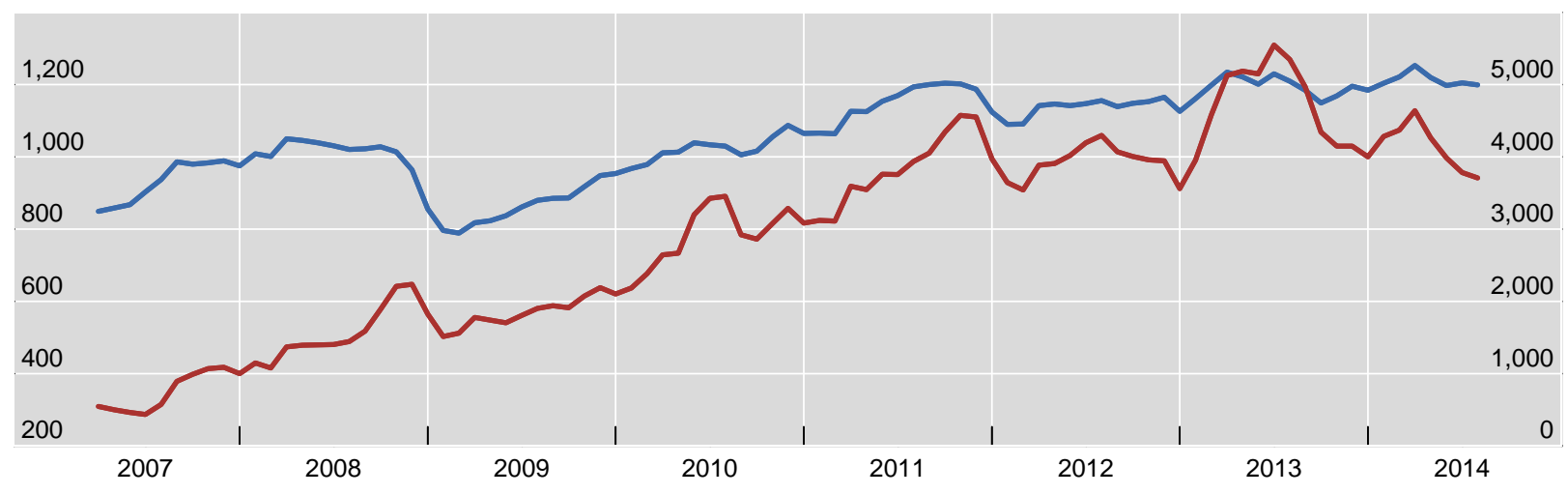

Lhs: Rhs:

Number of transactions (thousands) Value of trades (In billions of US dollars)

Note: Data reflect matched trades that were entered into on date $t$ rather than settled trades that were entered into at some earlier time for settlement on date $t$.

Sources: CLS; authors' calculations. 


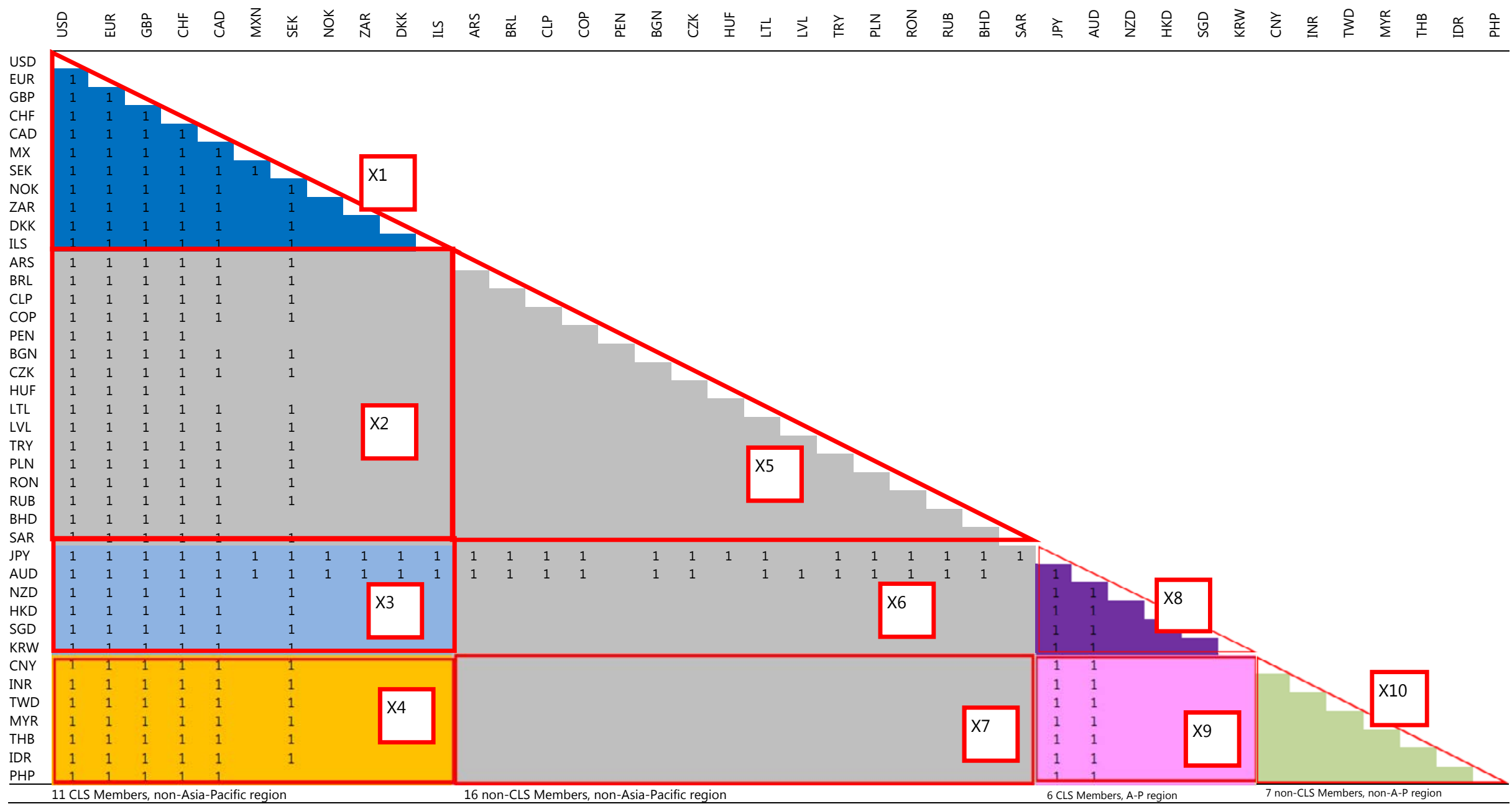


Note for Graph 32: The 2013 BIS Survey has positive turnover data for all cells marked with "1". Regions X1, X3 and X8 designate all pairs of CLS-enabled currencies. All other regions are currency pairs that cannot settle through CLS. Trades between the INR or MYR or IDR and the USD are eligible for PVP settlement through the RENTAS system or the HKMA.

Q1) \% trades, any pair, enabled for CLS:

$\mathrm{X} 1+\mathrm{X} 3+\mathrm{X} 8) / \operatorname{sum}(\mathrm{X} 1, \ldots \mathrm{X} 10)$

Q2) \% trades of AP/AP enabled for CIS:

$\mathrm{X} 8 /(\mathrm{X} 8+\mathrm{X} 9+\mathrm{X} 10)$

Q3) \% trades of NAP/NAP enabled for CLS

$\mathrm{X} 1 /(\mathrm{X} 1+\mathrm{X} 2+\mathrm{X} 5)$

Q4) \% trades of AP/(AP or NAP) enabled for CLS: $\quad(X 3+X 8) /(X 3+X 4+\operatorname{sum}[X 6 \ldots . X 10])$

Q5) \% trades of NAP/(AP or NAP) enabled for CLS: $\quad(X 1+X 3) /$ sum $[X 1, \ldots X 7]$

Add INR, MYR and IDR volume to Q1, Q4 and Q5 numerator to measure \% enabled for CLS or PVP 
Cumulative total return of a G10 $3 \times 3$ carry trade basket, February 1980-August 2014

February $1989=100$

Graph 5.1

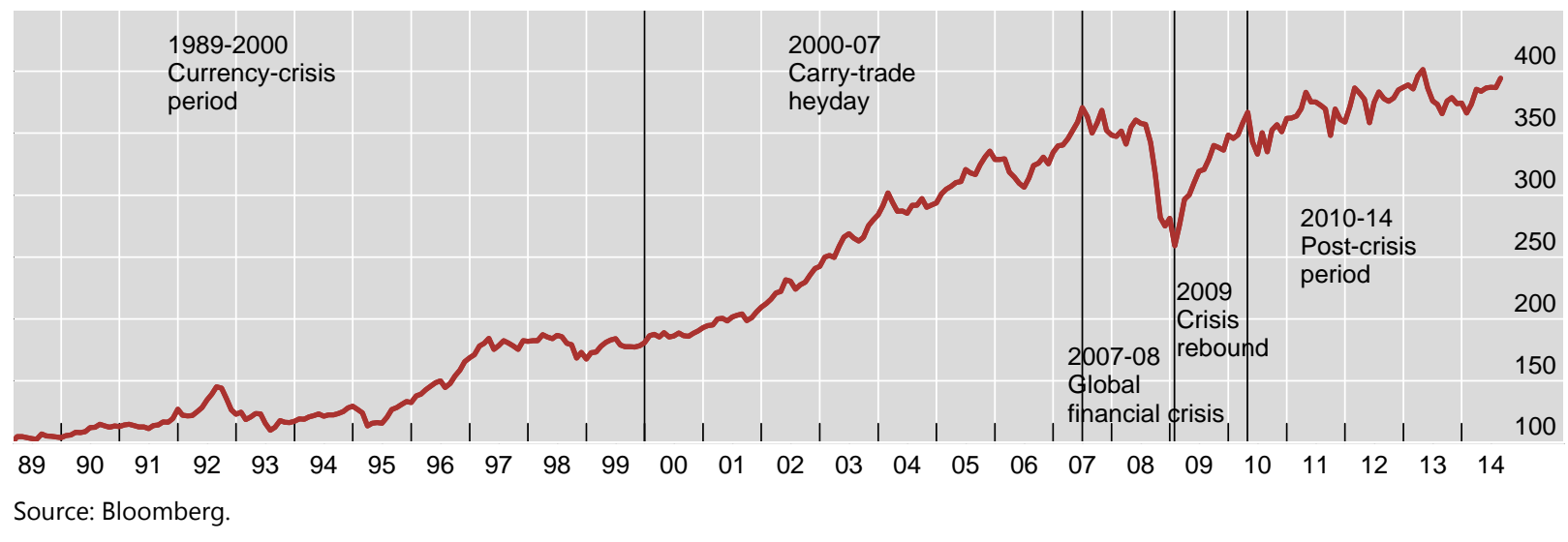

Cumulative total return of an EM $3 \times 3$ carry trade basket, December 2000-August 2014

December $2000=100$

Graph 5.2

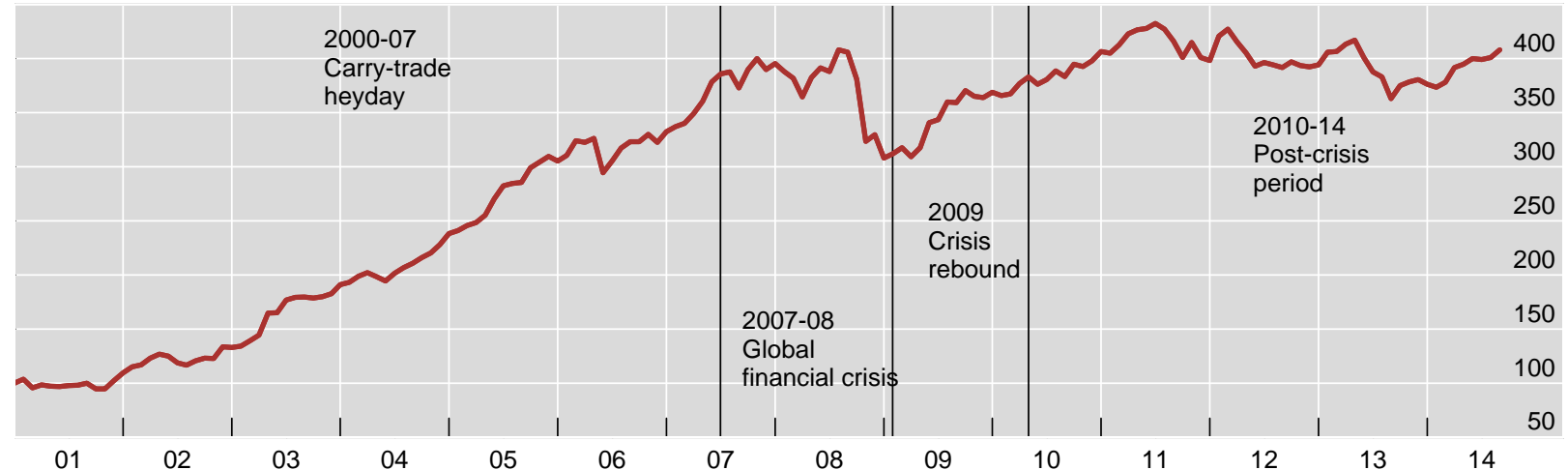

Source: Bloomberg. 


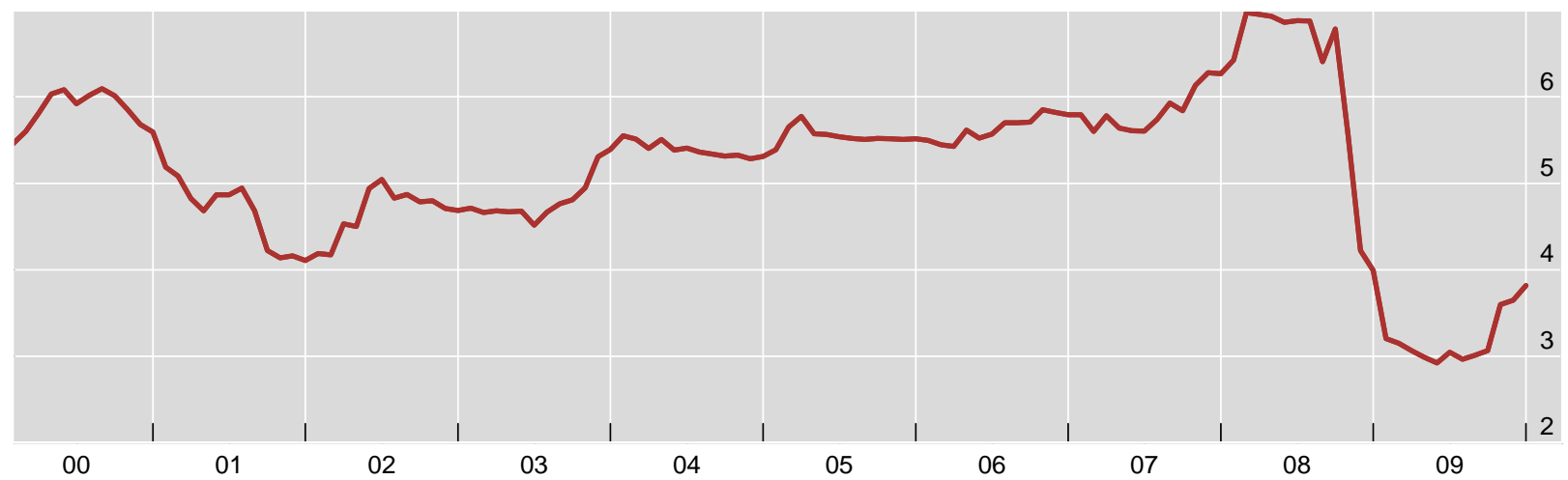

${ }^{1}$ Three-month LIBOR interest rate differential between Australian dollar and Japanese yen, end of month.

Sources: Bloomberg; authors' calculations.

\section{Exchange rate and carry trade attractiveness}

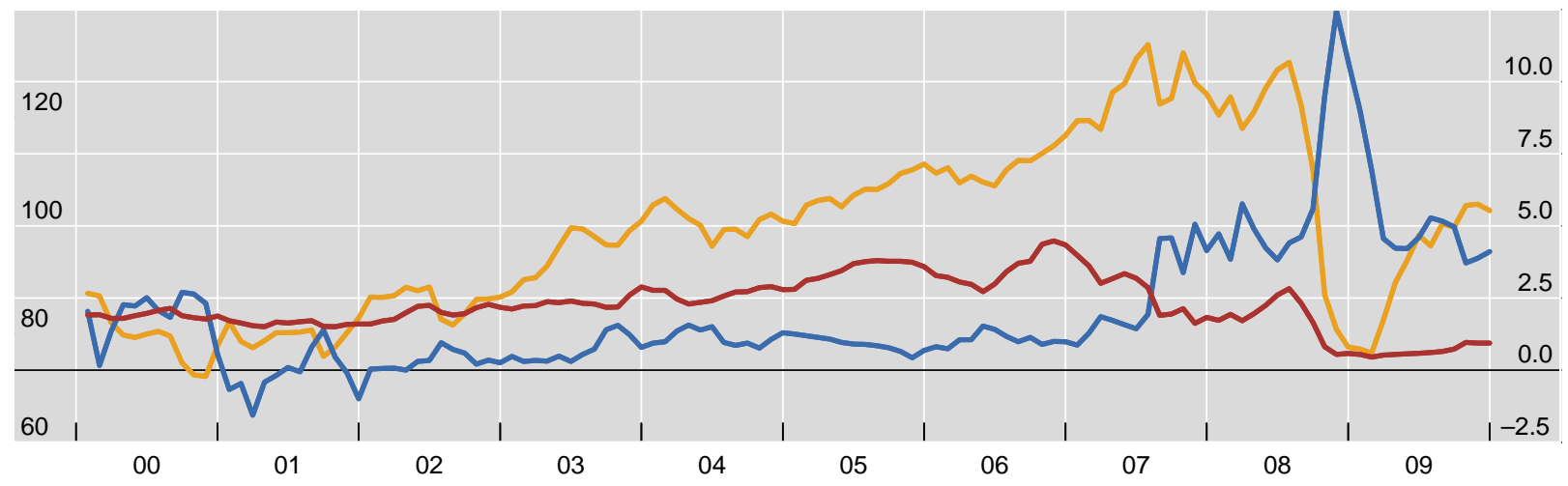

Lhs: AUD $/ J P Y^{1} \quad$ Rhs: Carry-to-risk $^{2}$

1 2002-06 = 100. ${ }^{2}$ Defined as the three-month interest rate differential divided by the implied volatility derived from three-month atthe-money exchange rate options; quintuple scale (eg the number 2 represents a ratio of 0.4 ). ${ }^{3} 25$ delta; a positive value indicates a willingness to pay more to hedge against a yen appreciation.

Sources: Bloomberg; JPMorgan Chase; authors' calculations. 


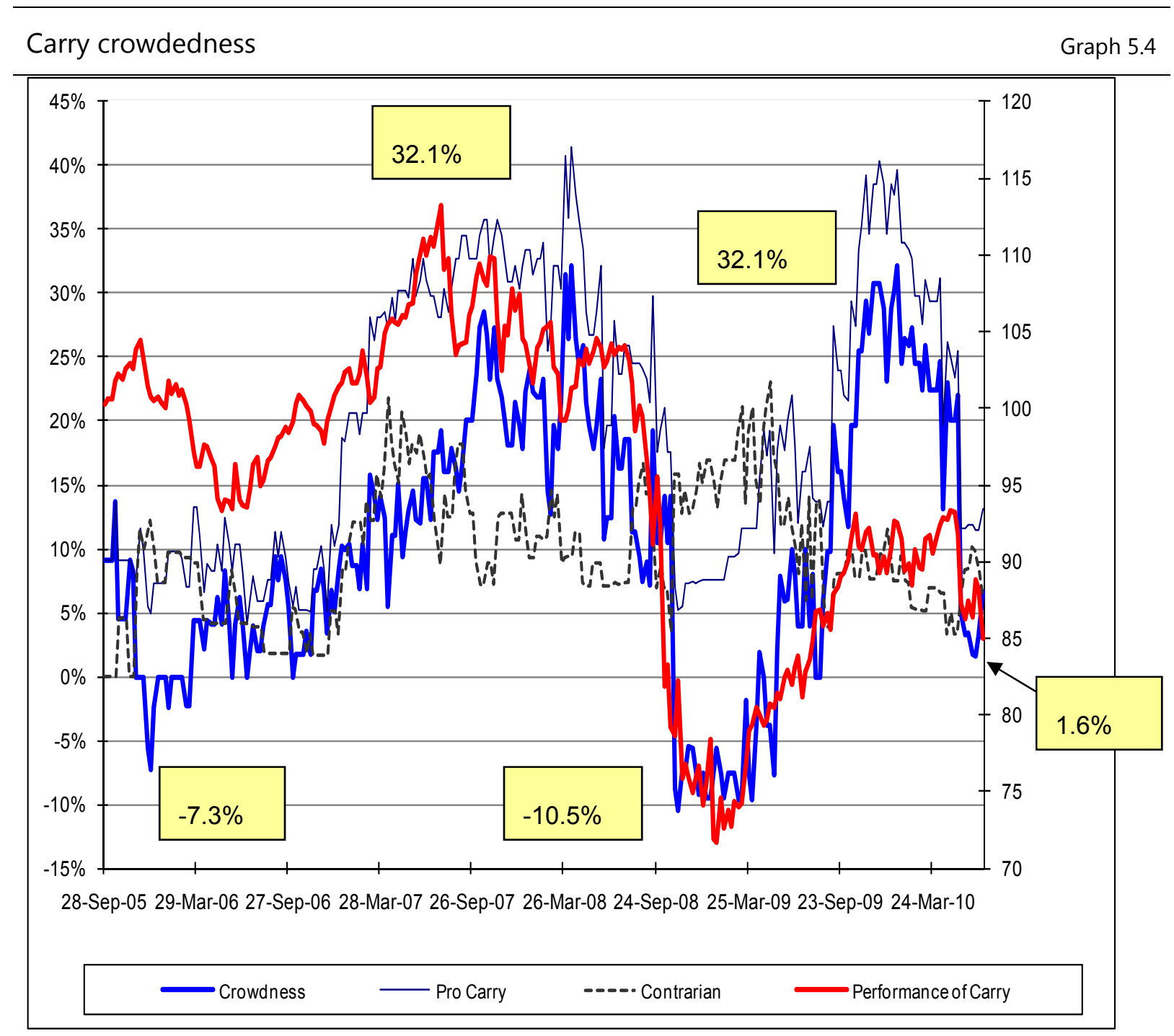

Source: Pojarliev and Levich (2011). 


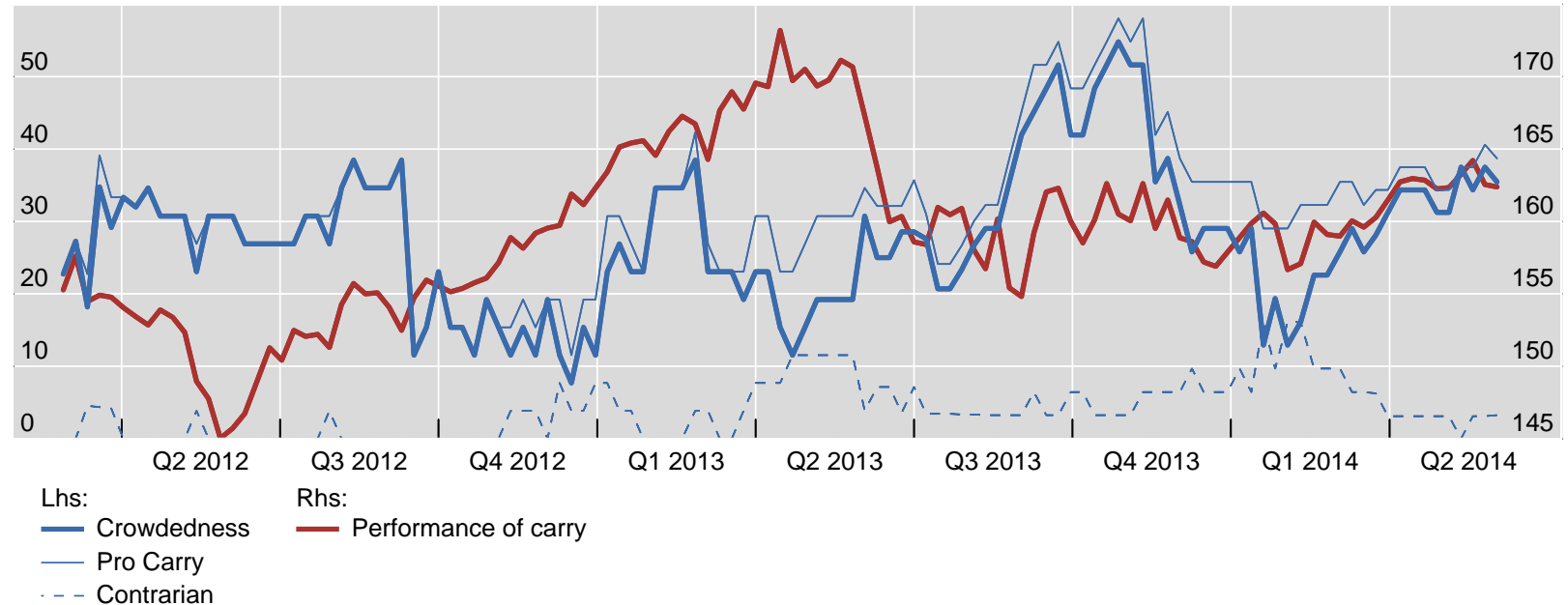

${ }^{1}$ Carry crowdedness is defined as the percentage of managers with significant style betas for carry less the percentage of managers with significant negative style betas against carry, where the DB G10 Carry Index is used as a proxy for carry trade returns. The first measure for crowdedness is estimated as of 2/22/2012 with 26 weekly observations from 8/31/2011 until 2/22/2012. The last measure of crowdedness is estimated as of 5/28/2014 with 26 weekly observations from 12/4/2013 until 5/28/2014. The sample contains 119 rolling windows.

Source: Bloomberg. 


\section{Chinese renminbi}

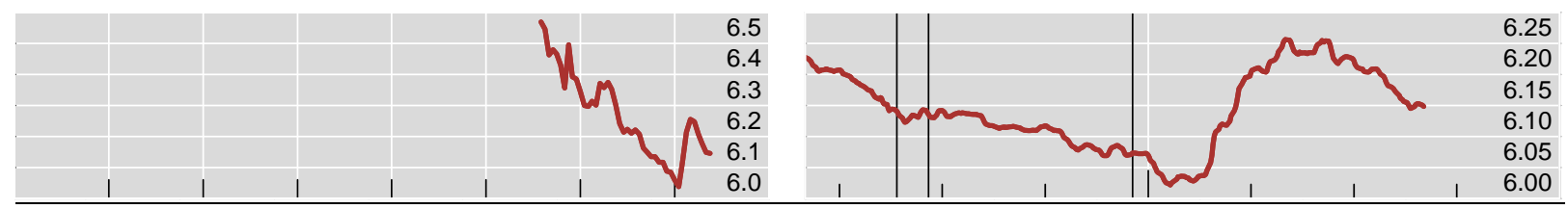

\section{India rupee}

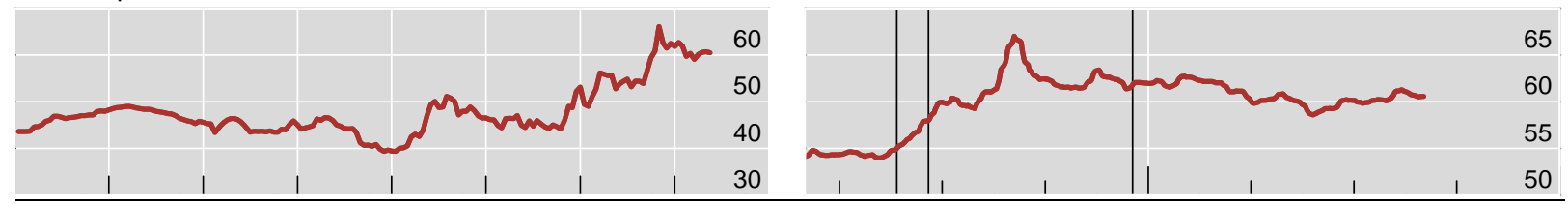

Indonesia rupiah
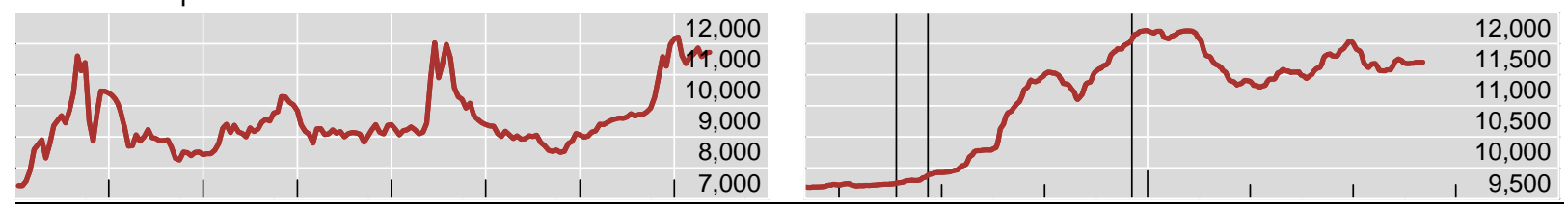

\section{Korean won}
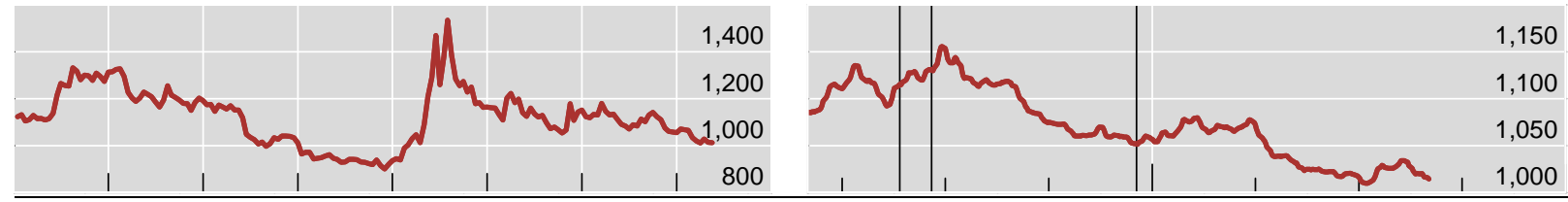

Malaysia ringgit
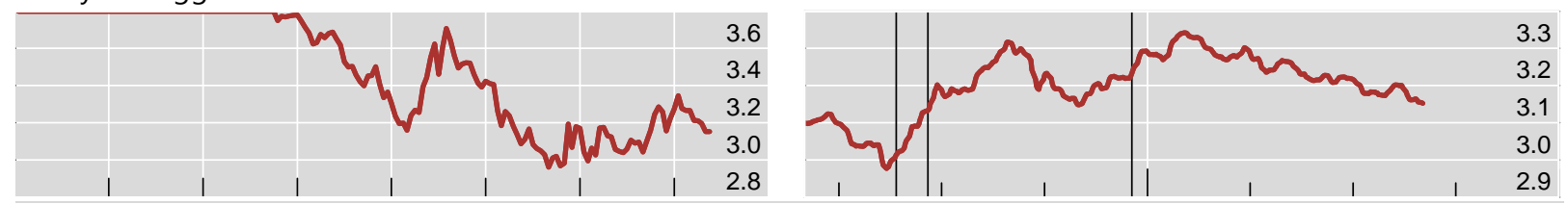

Philippine peso
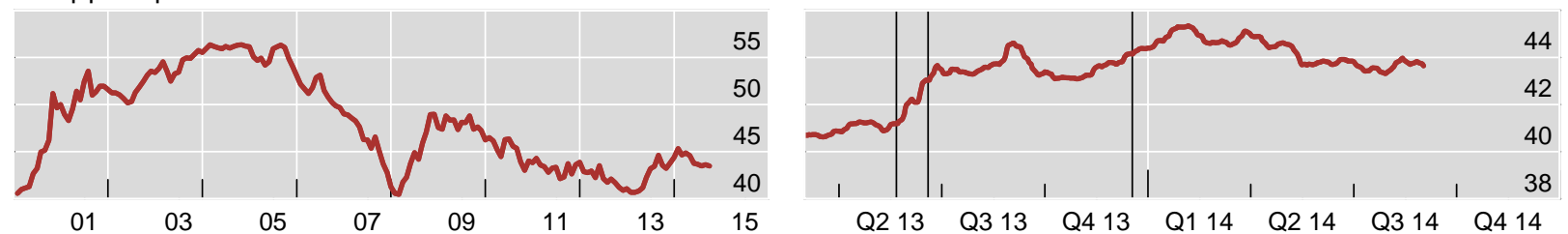

The three vertical lines indicate 22 May, 19 June and 18 December 2013.

${ }^{1}$ An increase indicates a depreciation of local currency.

Sources: Datastream, WM/Reuters; authors' calculations. 


\section{Singapore dollar}

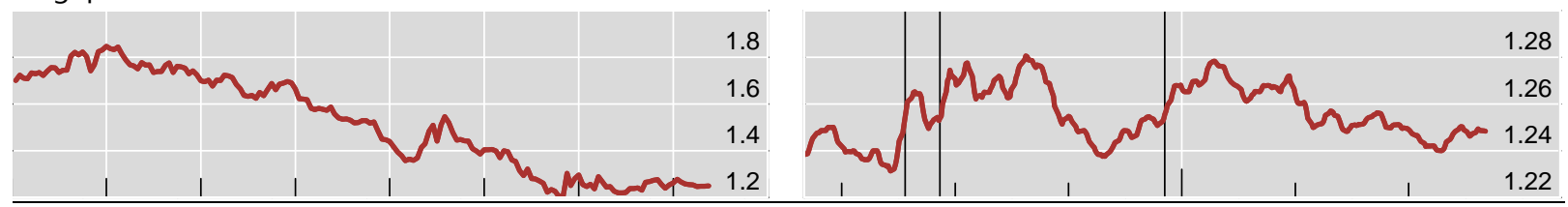

Thai baht

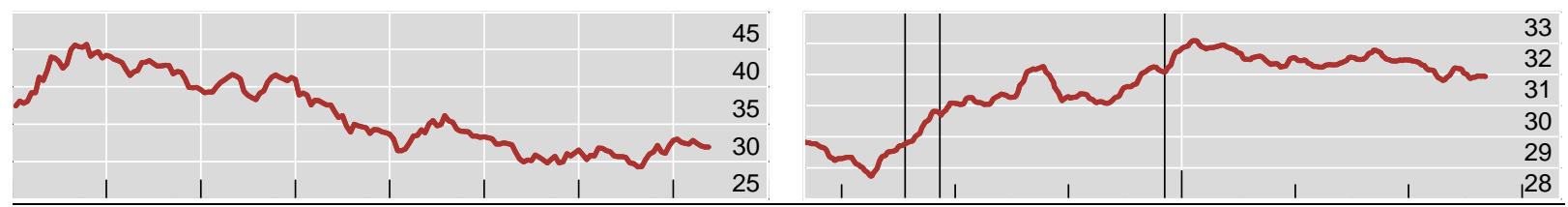

Australian dollar

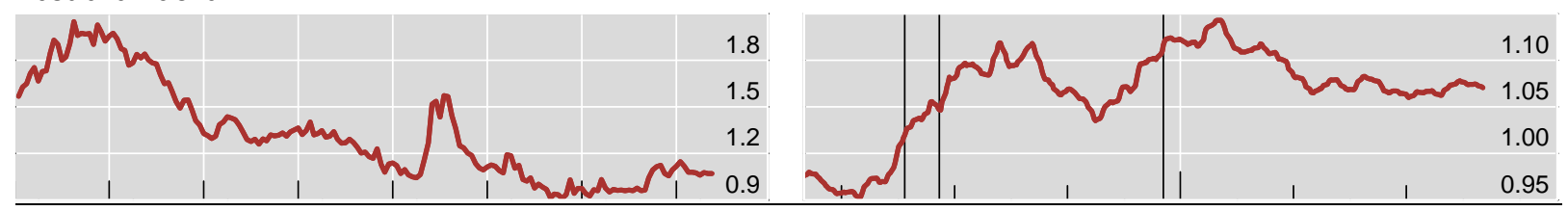

Japanese yen

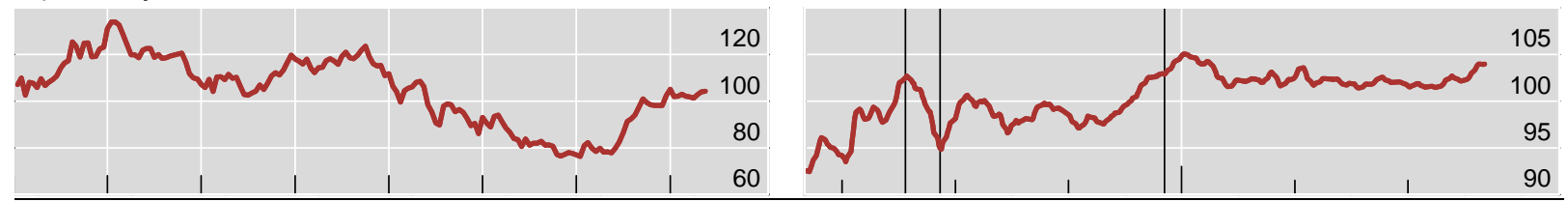

New Zealand dollar

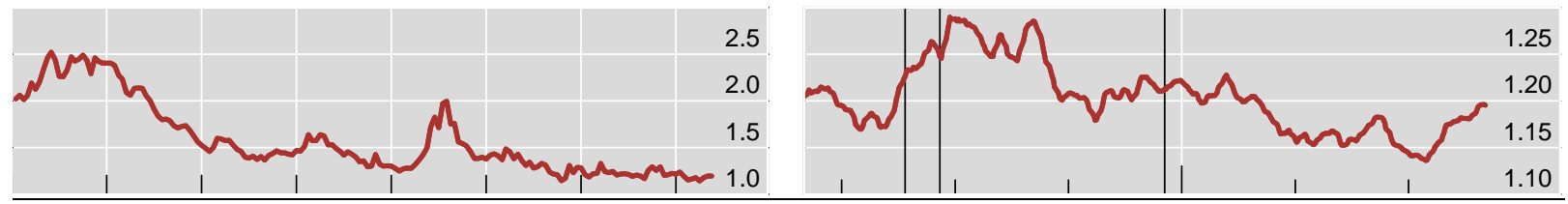

Hong Kong dollar
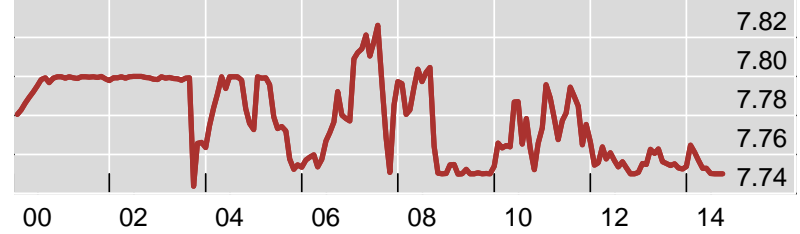

04

06

08

$\begin{array}{lll}10 & 12 & 14\end{array}$

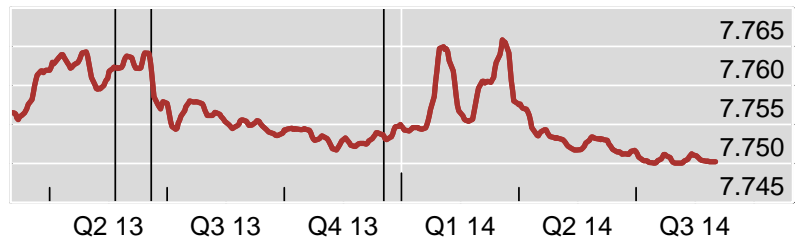

The three vertical lines indicate 22 May, 19 June and 18 December 2013.

${ }^{1}$ An increase indicates a depreciation of local currency.

Sources: Datastream, WM/Reuters; authors' calculations. 
Chinese renminbi

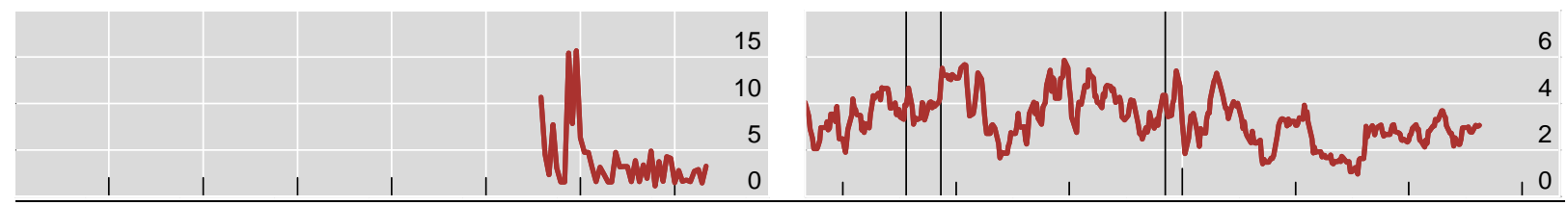

India rupee

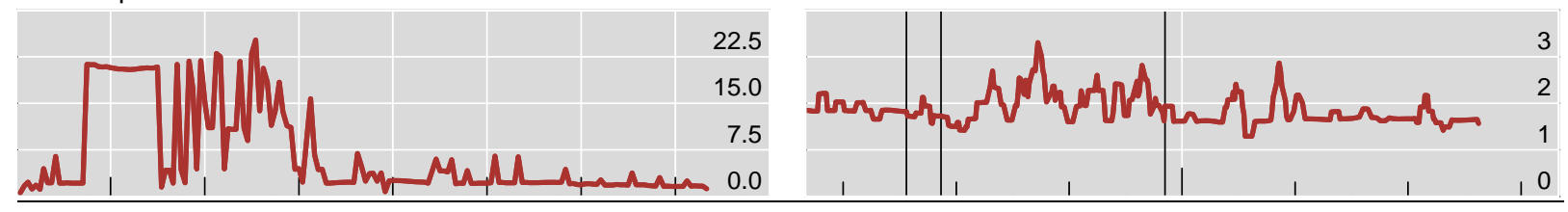

Indonesia rupiah

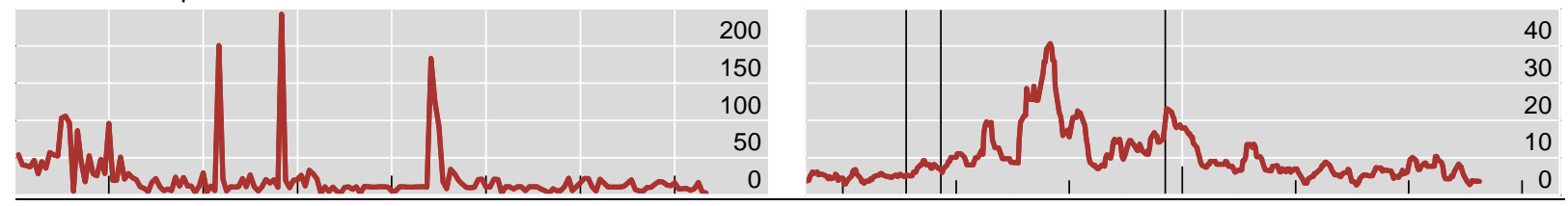

Korean won

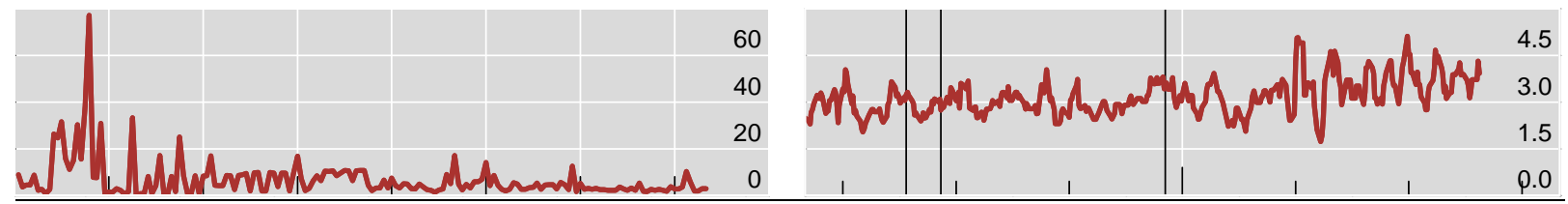

Malaysia ringgit

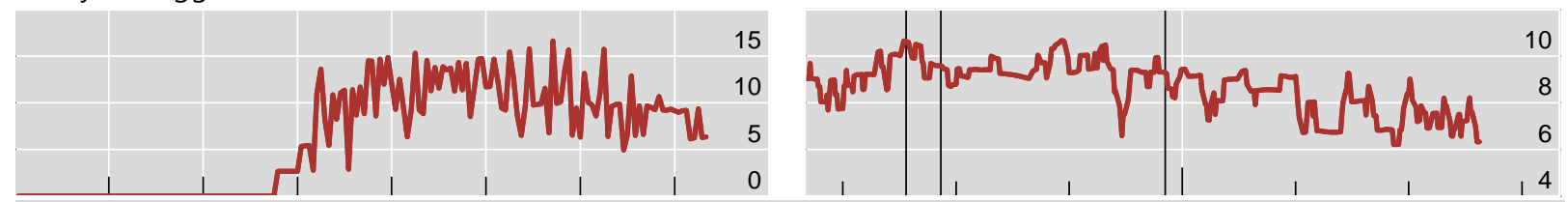

Philippine peso
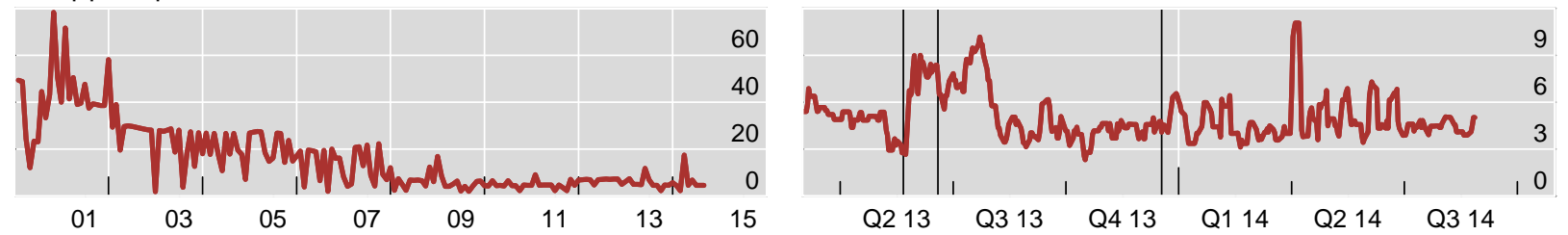

The three vertical lines indicate 22 May, 19 June and 18 December 2013.

${ }^{1}$ Relative bid-ask spreads are expressed in basis points against the mid-quote; indicative quotes against the US dollar. Sources: Datastream, WM/Reuters; authors' calculations. 


\section{Singapore dollar}

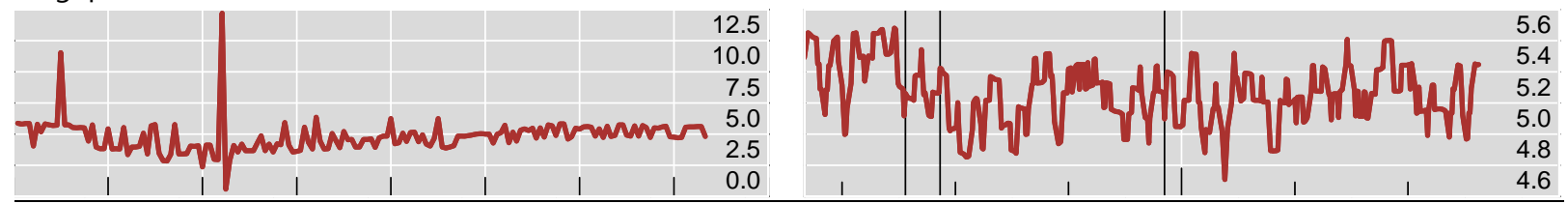

Thai baht

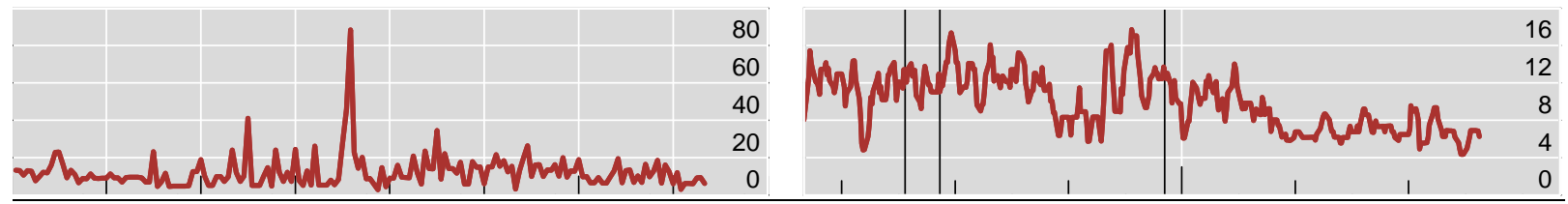

\section{Australian dollar}

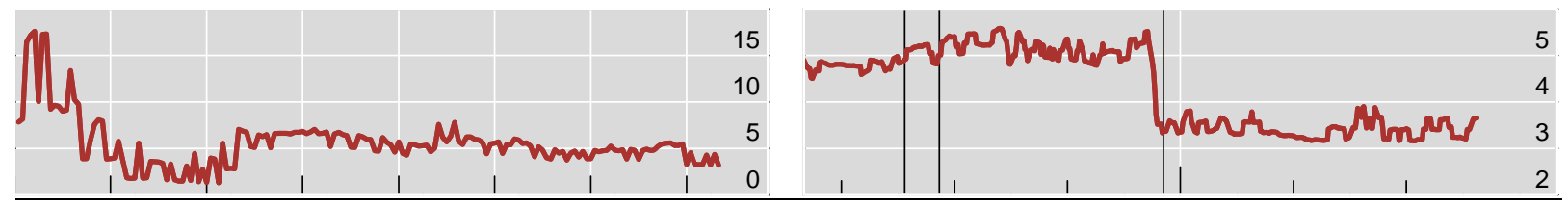

Japanese yen

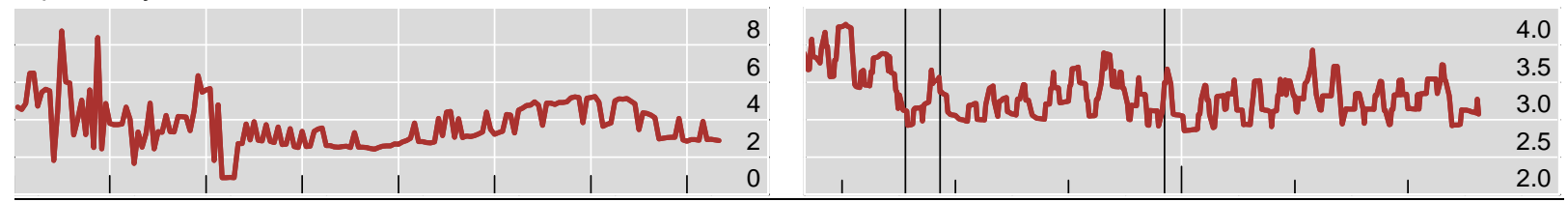

New Zealand dollar

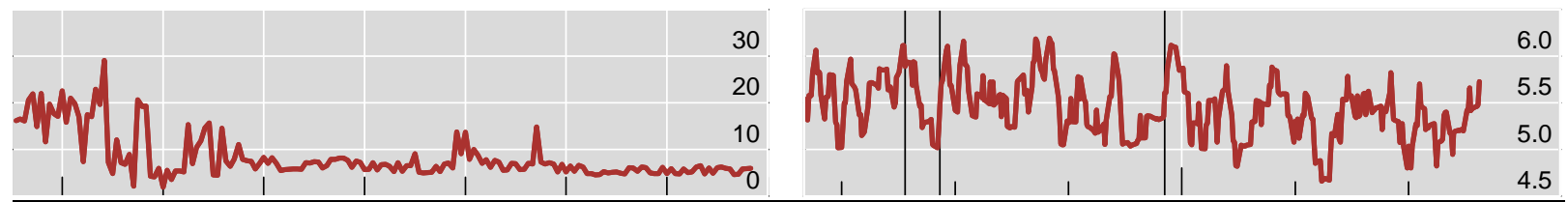

\section{Hong Kong dollar}

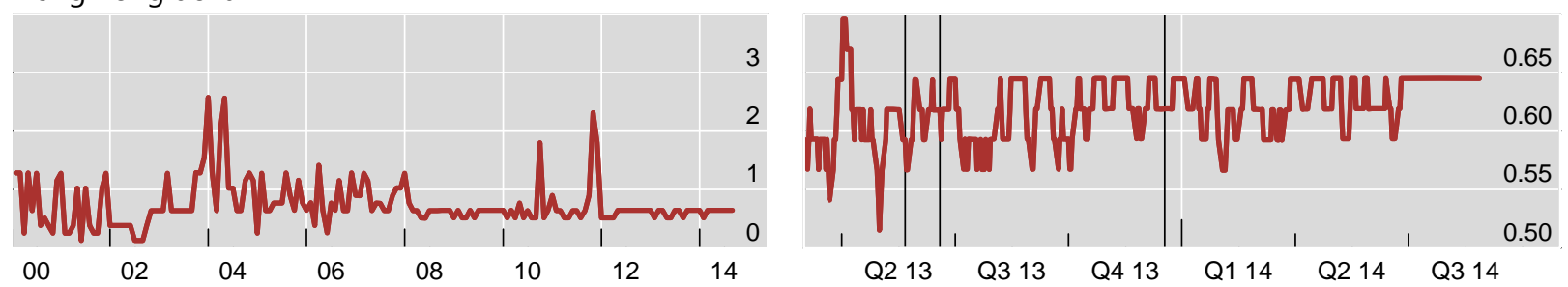

The three vertical lines indicate 22 May, 19 June and 18 December 2013.

${ }^{1}$ Relative bid-ask spreads are expressed in basis points against the mid-quote; indicative quotes against the US dollar. Sources: Datastream, WM/Reuters; authors' calculations. 
Implied volatility

Against the US dollar, at the money, in per cent

2000-14, month-end data

2013-14, five-day moving average

Chinese renminbi

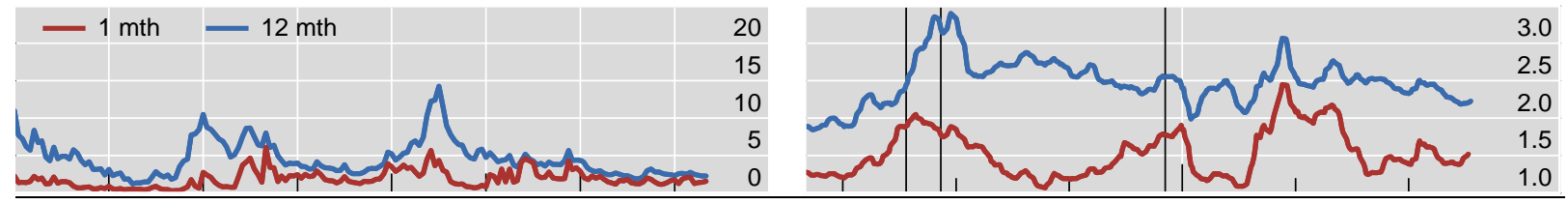

India rupee

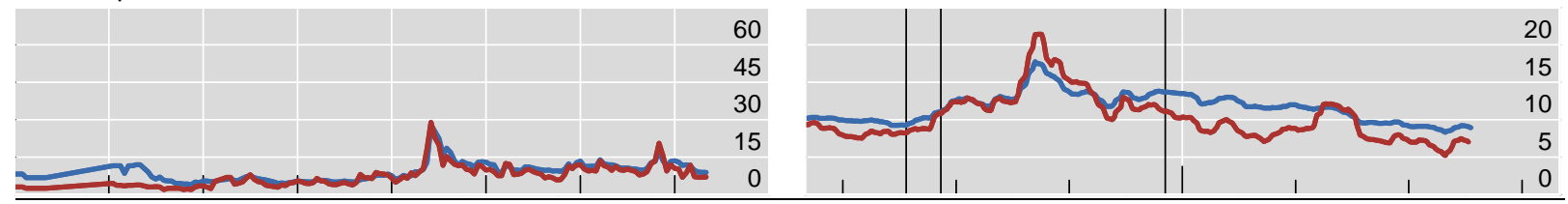

Indonesia rupiah

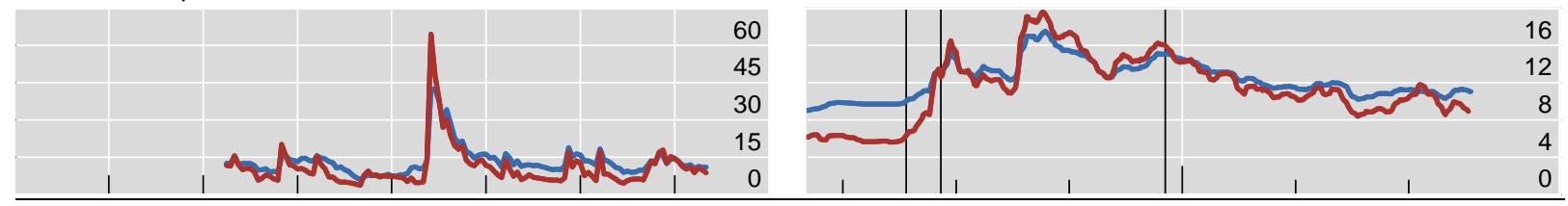

\section{Korean won}

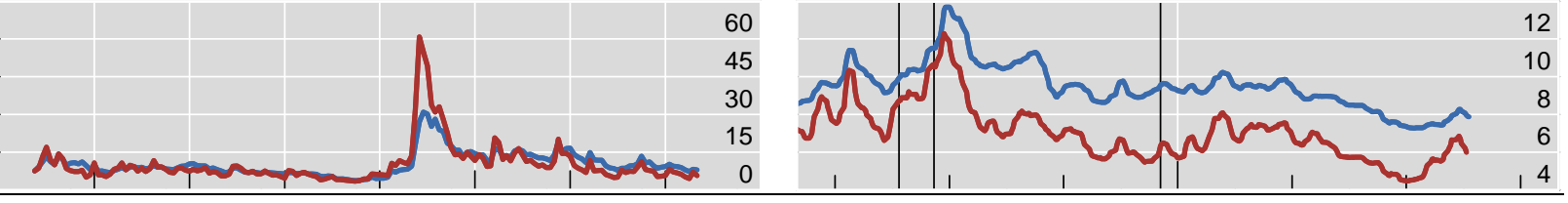

Malaysia ringgit

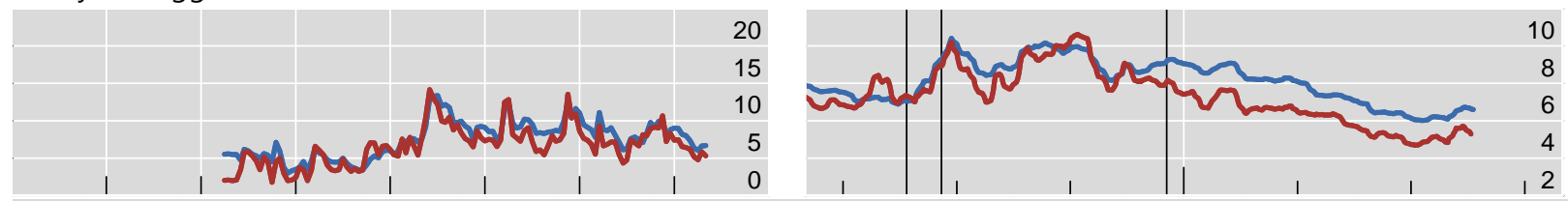

Philippine peso

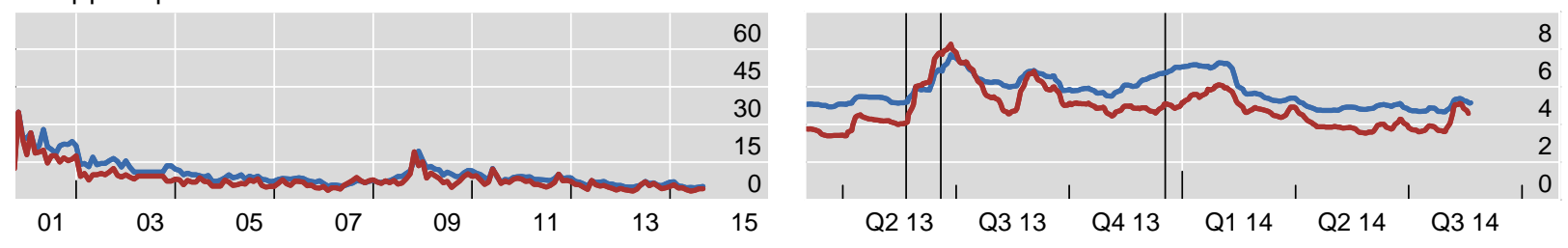

The three vertical lines indicate 22 May, 19 June and 18 December 2013.

Source: JPMorgan Chase. 
Implied volatility (cont)

Against the US dollar, at the money, in per cent

Singapore dollar

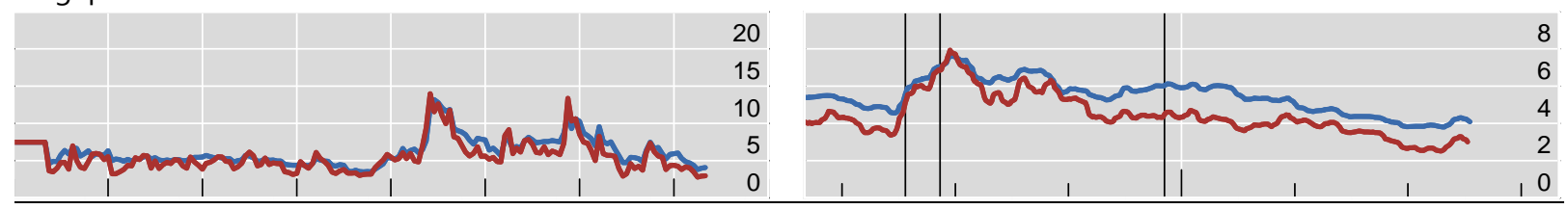

Thai baht

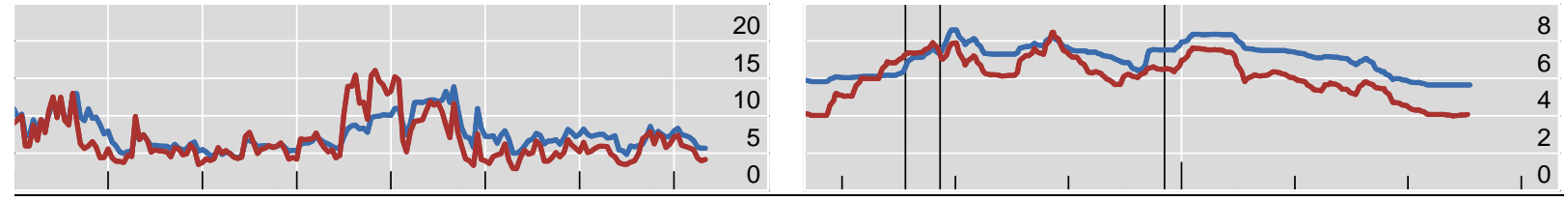

\section{Australian dollar}

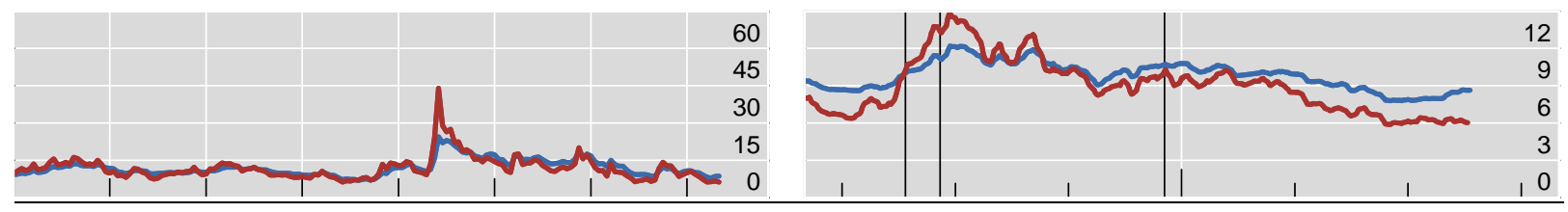

Japanese yen

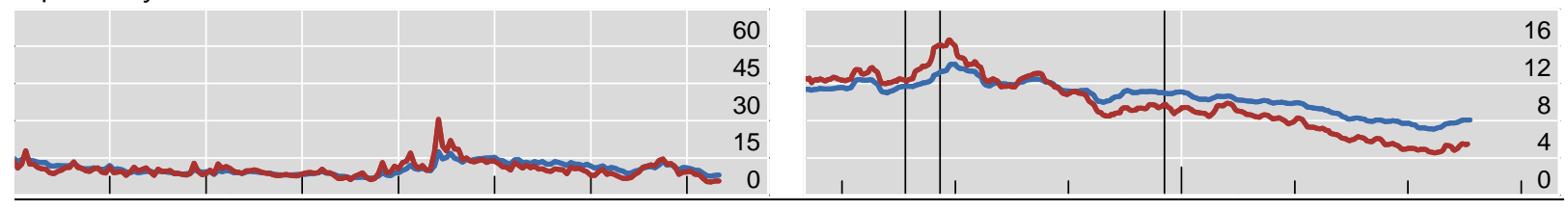

New Zealand dollar

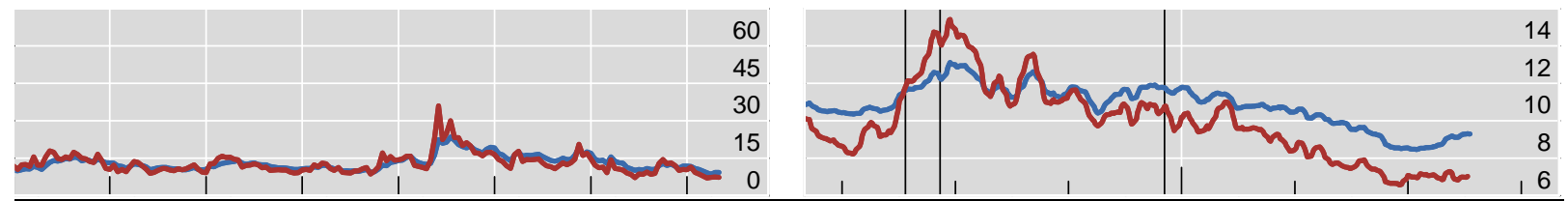

Hong Kong dollar
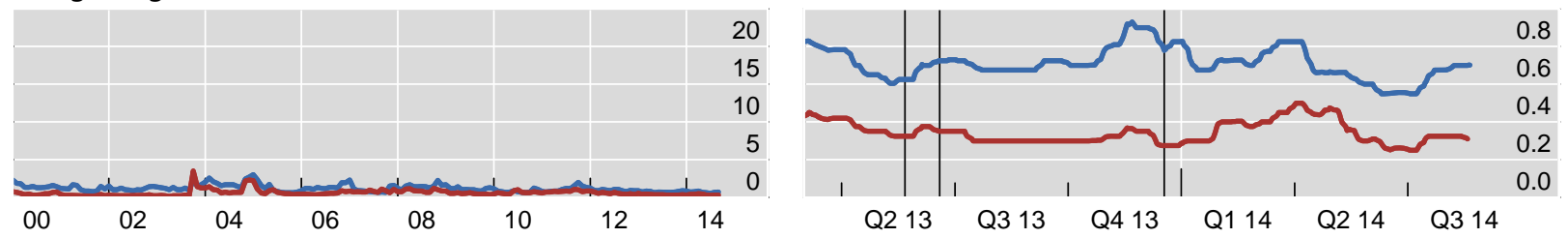

The three vertical lines indicate 22 May, 19 June and 18 December 2013.

Source: JPMorgan Chase. 
Realised volatility

Against the US dollar, in percent

2000-14, monthly data ${ }^{1}$

Chinese renminbi

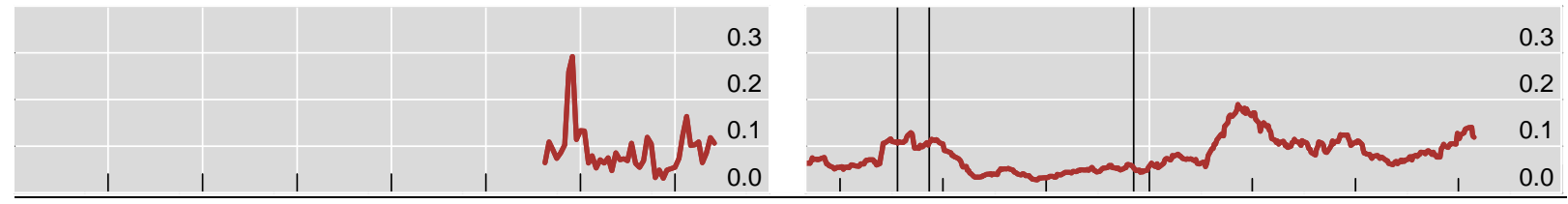

India rupee

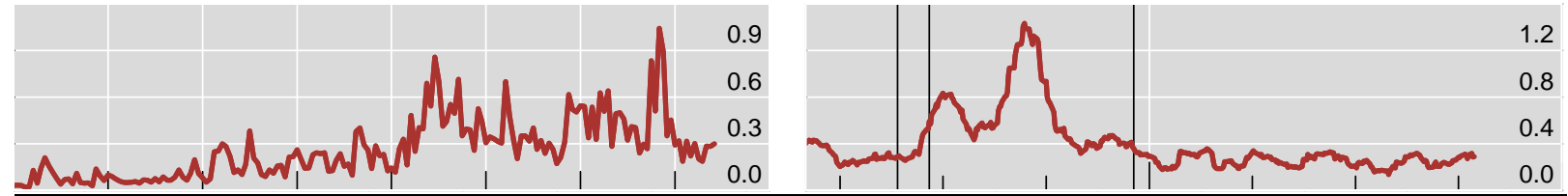

Indonesia rupiah

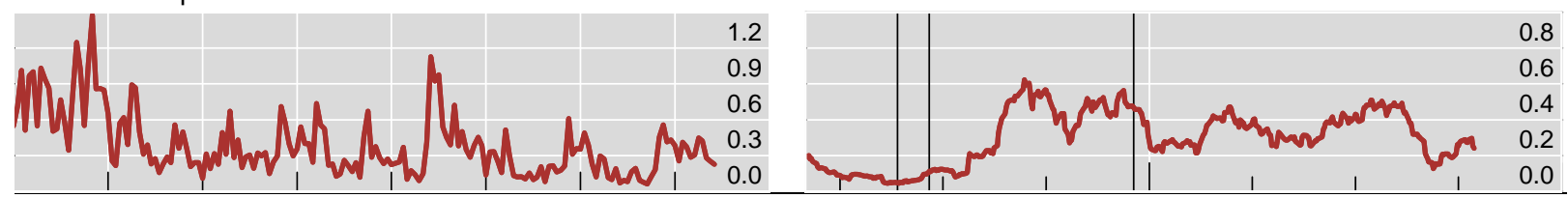

Korean won

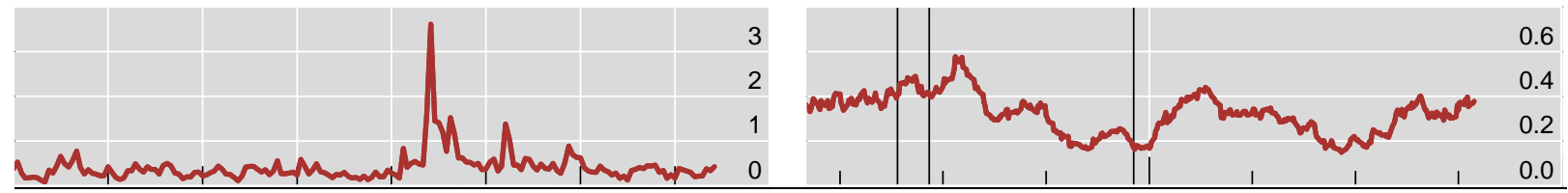

Malaysia ringgit

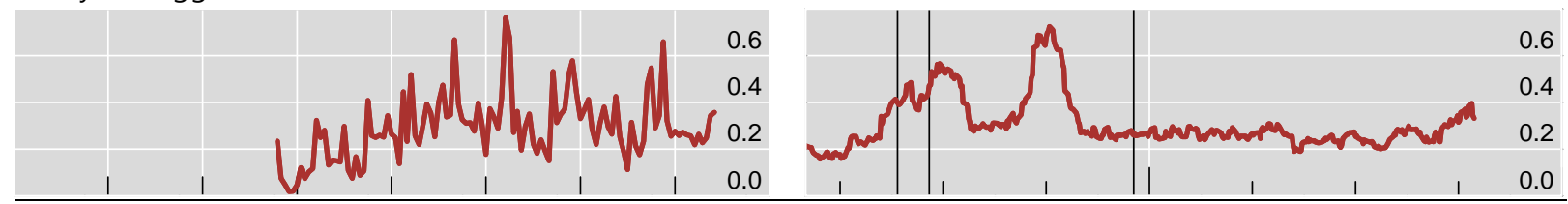

\section{Philippine peso}
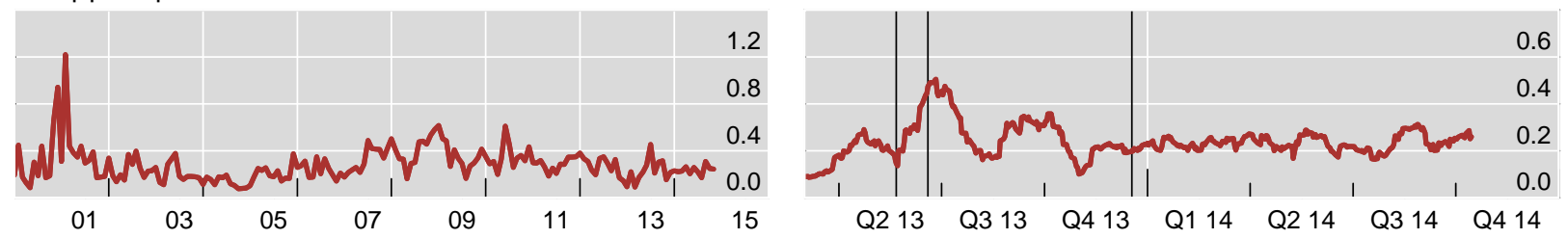

${ }^{1}$ Computed as the monthly averages of daily absolute returns.

2013-14, monthly moving average

Sources: Datastream, WM/Reuters; authors' calculations. 
Realised volatility (cont)

Against the US dollar, in percent

Annex Graph 4

2000-14, monthly data ${ }^{1}$

2013-14, monthly moving average

Singapore dollar

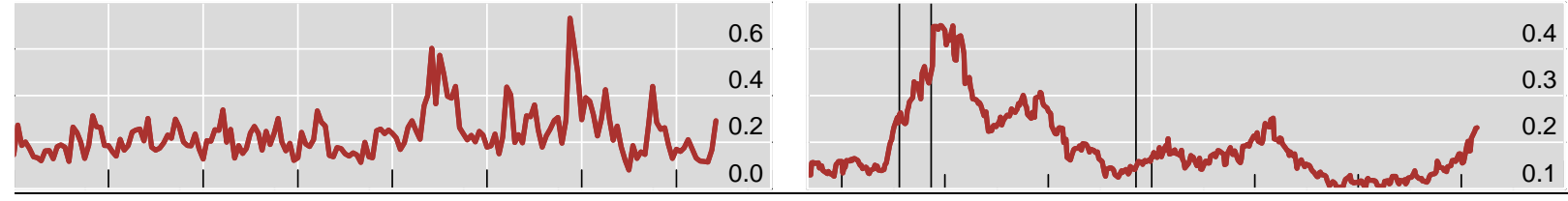

Thai baht

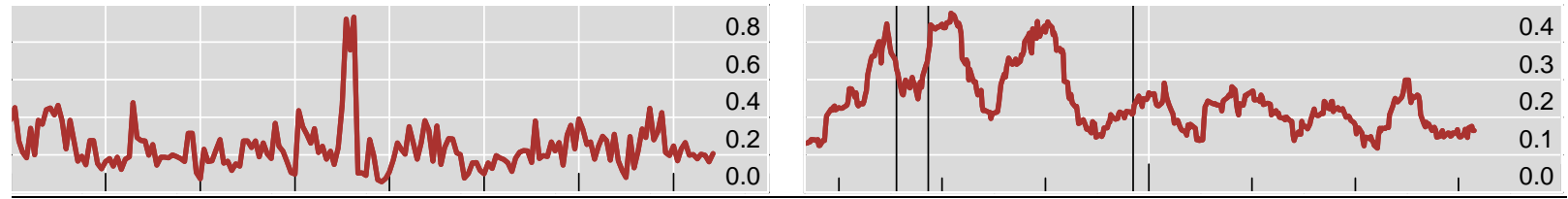

Australian dollar

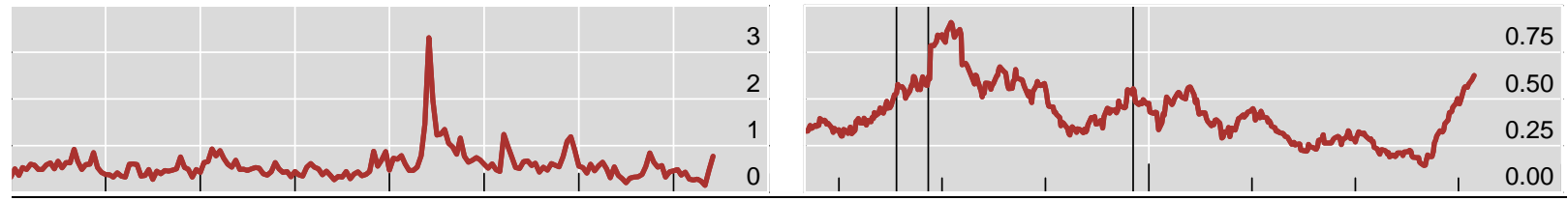

Japanese yen

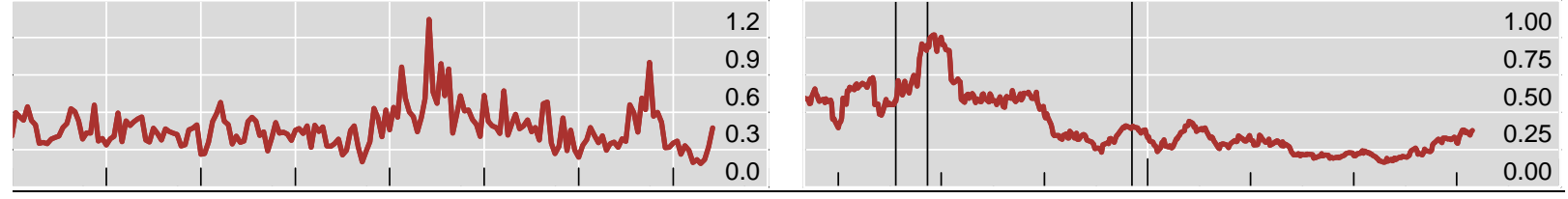

New Zealand dollar
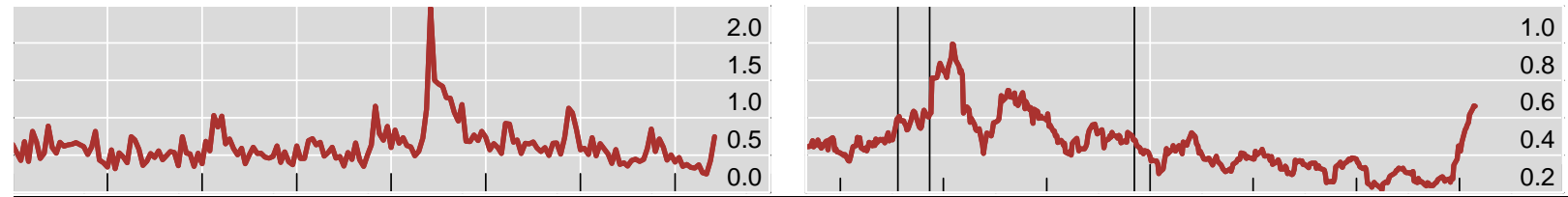

Hong Kong dollar
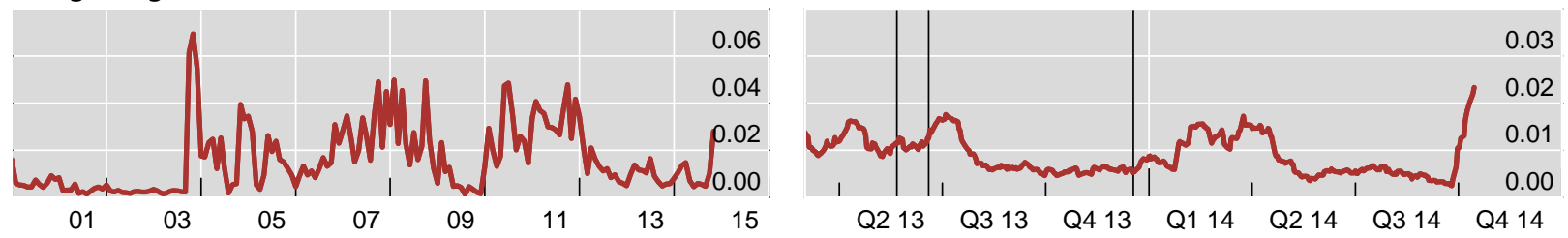

${ }^{1}$ Computed as the monthly averages of daily absolute returns.

Sources: Datastream, WM/Reuters; authors' calculations. 

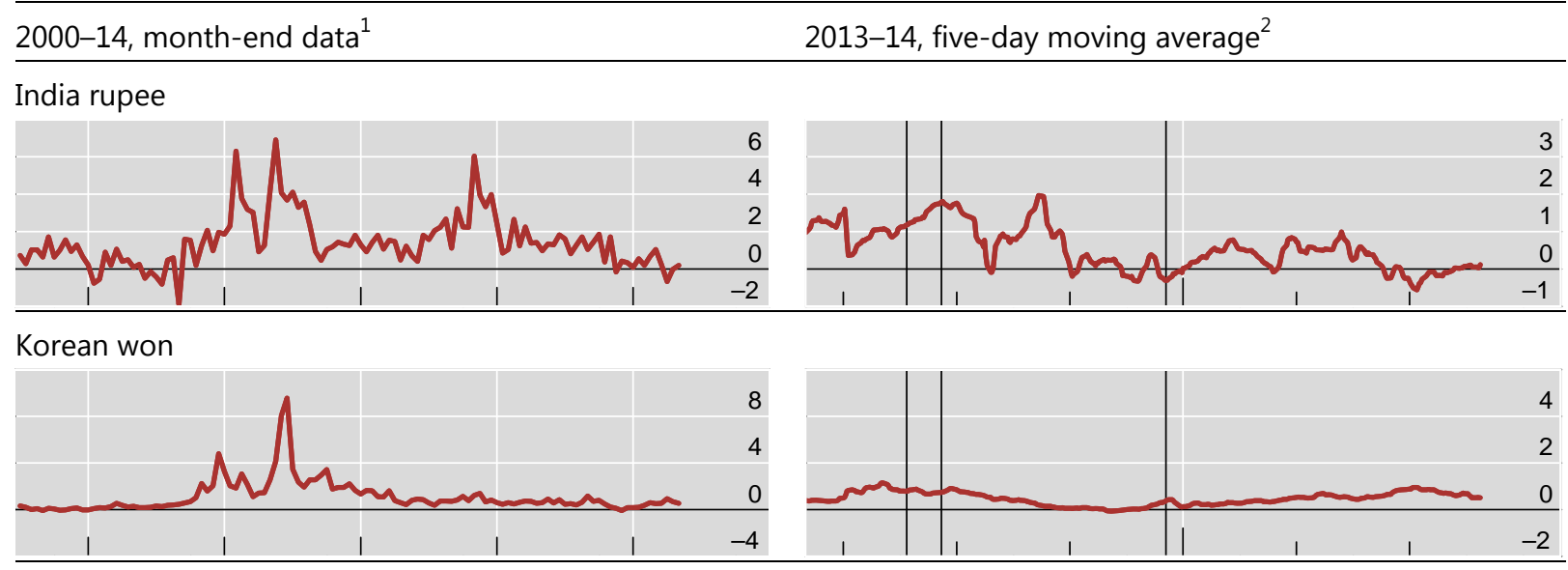

Philippine peso

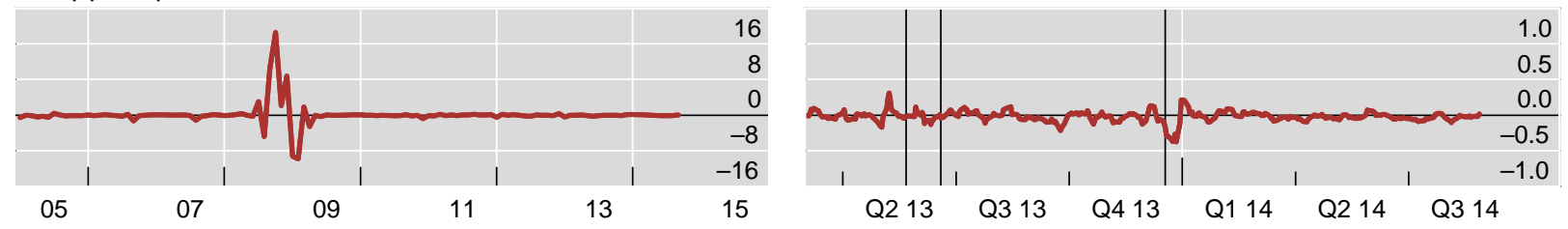

Japanese yen

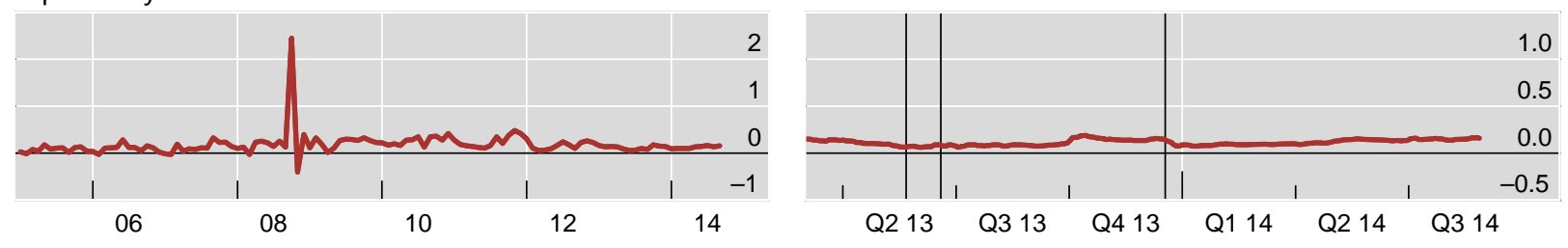

${ }^{1}$ Computed as the difference between the three-month FX swap-implied US dollar interest rate and three-month US dollar Libor, in per cent, end of month. The former is derived from the covered interest parity condition based on the following domestic three-month interest rates.

Sources: Bloomberg, Datastream, authors' calculations. 
Onshore less offshore foreign exchange forward premia ${ }^{1}$

As a \% of spot price, for three-month contracts

Chinese renminbi
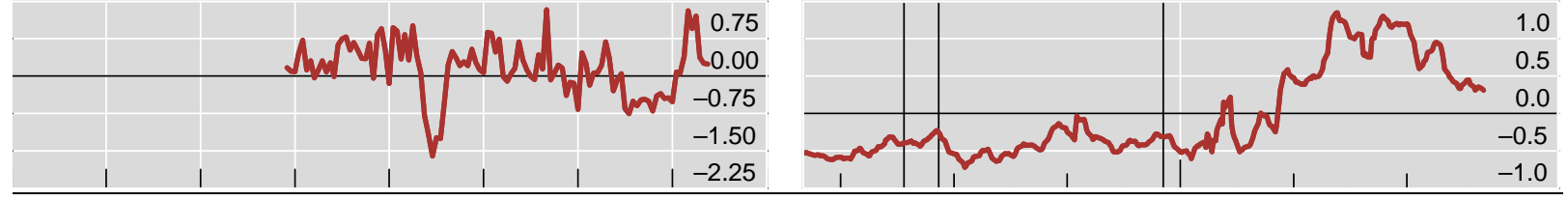

Indian rupee

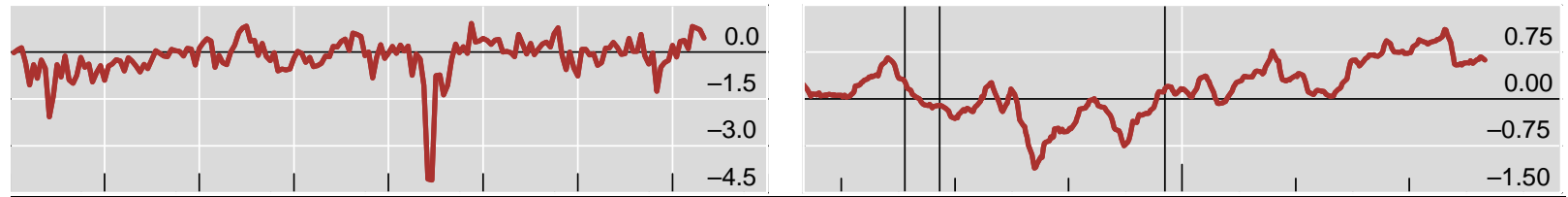

Indonesian rupiah

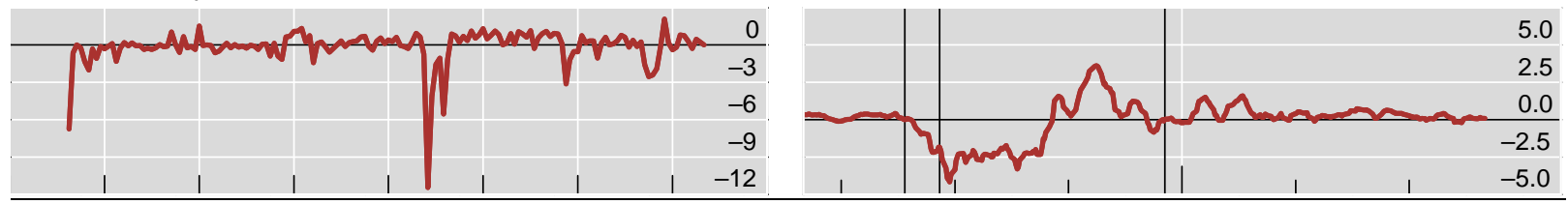

\section{Korean won}

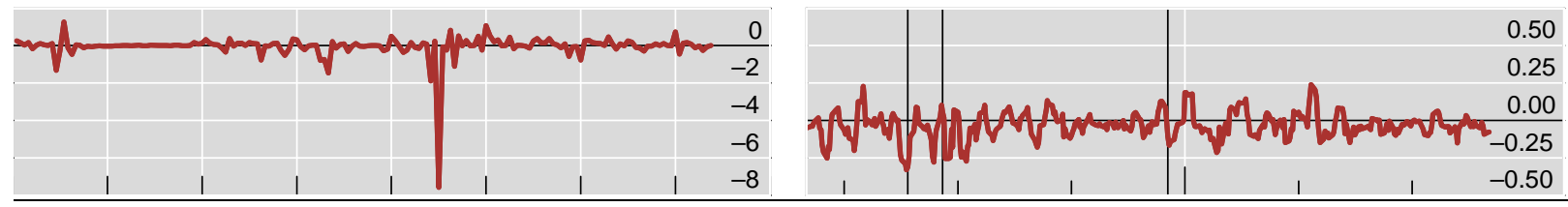

Malaysia ringgit

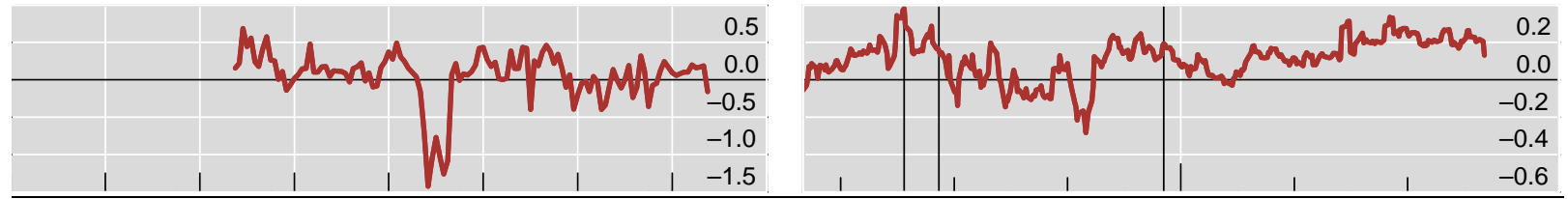

Philippines peso
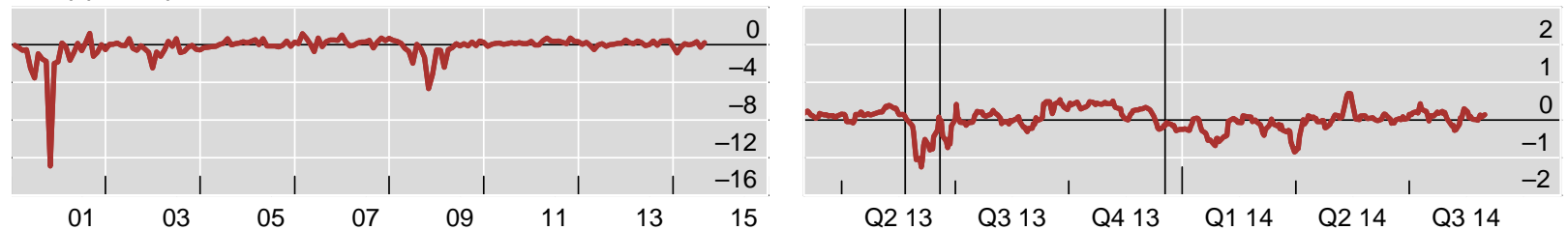

The three vertical lines indicate 22 May, 19 June and 18 December 2013.

${ }^{1}$ The forward premia are calculated as the difference between onshore forward and offshore NDF rates as a percentage of the spot price. Sources: Bloomberg; authors' calculations. 


\section{References}

Alys, K (2012): "Spotlight on: David Puth, CLS", FX Week, 22 October.

Aizenman, J, M Binici and M Hutchison (2014): "The transmission of Federal Reserve tapering news to emerging financial markets", NBER Working Papers, no 19980, National Bureau of Economic Research.

Baba, N and F Packer (2009a) "Interpreting deviations from covered interest parity during the financial market turmoil of 2007-08", Journal of Banking and Finance, November.

(2009b): "From turmoil to crisis: Dislocations in the FX swap market before and after the failure of Lehman Brothers", Journal of International Money and Finance, December.

Bank for International Settlements, Basel Committee on Banking Supervision (2013): "Supervisory guidance for managing risks associated with the settlement of foreign exchange transactions", February.

Bank for International Settlements, Committee on Payments and Market Infrastructures (2011): "Payment, clearing and settlement systems in India".

Bank for International Settlements, Committee on Payment and Settlement Systems (1996): "Settlement risk in foreign exchange transactions", (the Allsopp Report).

Bank for International Settlements (2013): Triennial Central Bank Survey of foreign exchange and derivatives market activity.

Bank of Thailand (2012): "Payment Systems Report".

Bech, M and J Sobrun (2013): "FX Market Trends before, between, and beyond Triennial Surveys", BIS Quarterly Review, December.

Bilson, J (1981): "The 'Speculative Efficiency' Hypothesis", Journal of Business, vol 54, no 3, July.

Brunnermeier, M, S Nagel and L Pedersen (2009): "Carry trades and currency crashes", NBER Macroeconomics Annual 2008, April.

Burnside, C, M Eichenbaum, I Kleshchelski and S Rebelo (2006): "The returns to currency speculation", NBER Working Paper, no 12489.

(2011): "Do peso problems explain the returns to the carry trade?", Review of Financial Studies, vol 24, no 3.

Cadarajat, Y and A Lubis (2012): "Offshore and onshore IDR market: an evidence on information spillover", Bulletin of Monetary Economics and Banking, April.

Clark, J (2013): "CLS Expansion will be key to EM currency growth", FX Week, July 19.

Curcuru, S, C Vega and J Hoek (2010): "Measuring carry trade activity", Irving Fisher Committee Bulletin, no 34, Bank for International Settlements.

Ehlers, T and F Packer (2013): "FX and derivatives markets in emerging economies and the internationalisation of their currencies", BIS Quarterly Review, December.

Eichengreen, B and P Gupta (2014): "Tapering talk: the impact of expectations of reduced federal reserve security purchases on emerging markets", Policy Research Working Paper Series, no 6754, World Bank. 
Feroli, M, A Kashyap, K Schoenholtz and H S Shin (2014): "Market tantrums and monetary policy", report prepared for the 2014 US Monetary Policy Forum, 28 February.

Financial Stability Oversight Council (2012): Annual Report.

Fratzcher, M (2009): "What explains global exchange rate movements during the financial crisis?", Journal of International Money and Finance, December.

Gabriele, G (2000): "Trading volumes, volatility and spreads in foreign exchange markets: evidence from emerging market countries", BIS Working Papers, no 93, Bank for International Settlements.

Galati, G, A Heath and P McGuire (2007): "Evidence of carry trade activity", BIS Quarterly Review, September.

Genberg, H, C Hui and T Chung (2011): "Funding liquidity risk and deviations from interest-rate parity during the financial crisis of 2007-2009", International Journal of Finance \& Economics, vol 16, no 4, October.

Goyal, R Jain and S Tewari (2013): "Non deliverable forward and onshore Indian rupee market: a study on inter-linkages", Reserve Bank of India, Working Paper Series, December.

Gyntelberg, J and A Schrimpf (2011): "FX Strategies in periods of distress." BIS Quarterly Review, December.

Hafeez, B (2013): "The rise (and fall?) of the China FX carry trade", Deutsche Bank Markets Research, 11 June.

Karnaukh, N, A Ranaldo and P Söderlind (2013): "Understanding FX liquidity", Working Papers on Finance, no 1315, University of St Gallen, School of Finance.

Kim, K and C Y Song (2010): "Foreign exchange liberalization and its implications: the case of the won", in W Peng and C Shu (eds), Currency internationalization: global experiences and implications for the renminbi, pp 78-111.

King, M, C Osler and D Rime (2011): "Foreign exchange market structure, players and evolution", Central Bank of Norway, working paper, no 10.

Magyar Nemzeti Bank (2013): "Report on payment systems".

Mancini, L, A Ranaldo, and J Wrampelmeyer (2013): "Liquidity in the foreign exchange market: measurement, commonality, and risk premiums", Journal of Finance, vol 68, no 5, October

McCauley, R and M Scatigna (2011): "Foreign exchange trading in emerging currencies: more financial, more offshore", BIS Quarterly Review, March.

McCauley, R, C Shu, and G Ma (2014): "Non-deliverable forwards: 2013 and beyond", BIS Quarterly Review.

McGuire, P and G von Peter (2009): "The US dollar shortage in global banking and the international policy response", BIS Working Papers, no 291, Bank for International Settlements, November.

Pagano, M and P Volpin (2012): "Securitization, disclosure and liquidity", Review of Financial Studies, vol 25, no 8.

Pedersen, L (2009): "When everyone runs for the exits", The International Journal of Central Banking, vol 5. 
Pojarliev, M and R Levich (2008): "Do professional currency managers beat the benchmark?" Financial Analysts Journal, vol 64, no 5, September/October.

(2010): "Trades of the living dead: style differences, style persistence and performance of currency fund managers?", Journal of International Money and Finance, vol 29, no 8, December.

(2011): "Detecting crowded trades in currency funds", Financial Analysts Journal, January/February.

(2012): A new look at currency investing, CFA Institute.

Rosenberg, M (2014): "The carry trade - the essentials of theory, strategy \& risk management", in M Pojarliev and R Levich (eds), The Role of Currency in Institutional Portfolios, Risk Books,

Rime, D and A Schrimpf (2013): "The anatomy of the global FX market through the lens of the 2013 Triennial Survey", BIS Quarterly Review, December.

Szalay, E (2014): "CLS set to add Russian ruble in November, source says", FX Week, 12 February.

US Treasury Department (2011): "Fact sheet: notice of proposed determination on foreign exchange swaps and forwards", press release, 29 April. 